\title{
Characterization of $\mathrm{CD} 8^{+} \mathrm{T}$ Cell Differentiation following SIV $\Delta$ nef Vaccination by Transcription Factor Expression Profiling
}

\author{
James M. Billingsley ${ }^{1,2}$, Premeela A. Rajakumar ${ }^{1,2}$, Michelle A. Connole ${ }^{1}$, Nadine \\ C. Salisch ${ }^{1,3}$, Sama Adnan ${ }^{1,2}$, Yury V. Kuzmichev ${ }^{1}$, Henoch S. Hong ${ }^{1}$, R. Keith Reeves ${ }^{1,4}$, \\ Hyung-joo Kang ${ }^{5}$, Wenjun $\mathrm{Li}^{5}$, Qingsheng Li ${ }^{6}$, Ashley T. Haase ${ }^{7}$, R. Paul Johnson ${ }^{1,2,8 *}$
}

1 Division of Immunology, New England Primate Research Center, Harvard Medical School, Southborough, Massachusetts, United States of America, 2 Yerkes National Primate Research Center, Emory University, Atlanta, Georgia, United States of America, 3 Crucell Holland BV, Leiden, The Netherlands, 4 Center for Virology and Vaccine Research, Beth Israel Deaconess Medical Center, Boston, Massachusetts, United States of America, 5 Division of Preventive and Behavioral Medicine, University of Massachusetts Medical Center, Worcester, Massachusetts, United States of America, 6 Nebraska Center for Virology and School of Biological Sciences, University of Nebraska-Lincoln, Lincoln, Nebraska, United States of America, 7 University of Minnesota, Microbiology Department, Minneapolis, Minnesota, United States of America, 8 Ragon Institute of MGH, MIT, and Harvard, Cambridge, Massachusetts, United States of America

*rpaul.johnson@emory.edu

Citation: Billingsley JM, Rajakumar PA, Connole MA Salisch NC, Adnan S, Kuzmichev YV, et al. (2015) Characterization of $\mathrm{CD} 8^{+} \mathrm{T}$ Cell Differentiation following SIV $\Delta$ nef Vaccination by Transcription Factor Expression Profiling. PLoS Pathog 11(3): e1004740. doi:10.1371/journal.ppat. 1004740

Editor: Daniel C. Douek, Vaccine Research Center, UNITED STATES

Received: September 18, 2014

Accepted: February 10, 2015

Published: March 13, 2015

Copyright: ๑ 2015 Billingsley et al. This is an open access article distributed under the terms of the Creative Commons Attribution License, which permits unrestricted use, distribution, and reproduction in any medium, provided the original author and source are credited.

Data Availability Statement: All relevant data are within the paper and its Supporting Information files.

Funding: This work was supported by National Institutes of Health grants Al071306, Al095985, and grant P51 OD011103 (formerly RR00168) from the Office of Research Infrastructure Programs. The funders had no role in study design, data collection and analysis, decision to publish, or preparation of the manuscript.

Competing Interests: The authors have declared that no competing interests exist.

\section{Abstract}

The onset of protective immunity against pathogenic SIV challenge in SIV $\Delta$ nef-vaccinated macaques is delayed for 15-20 weeks, a process that is related to qualitative changes in $\mathrm{CD}^{+} \mathrm{T}$ cell responses induced by SIV $\Delta$ nef. As a novel approach to characterize cell differentiation following vaccination, we used multi-target qPCR to measure transcription factor expression in naïve and memory subsets of $\mathrm{CD} 8+^{+} \mathrm{T}$ cells, and in SIV-specific CD8 ${ }^{+} \mathrm{T}$ cells obtained from SIV $\Delta$ nef-vaccinated or wild type SIVmac239-infected macaques. Unsupervised clustering of expression profiles organized naïve and memory $C D 8^{+} T$ cells into groups concordant with cell surface phenotype. Transcription factor expression patterns in SIV-specific CD8 ${ }^{+} T$ cells in SIV $\triangle$ nef-vaccinated animals were distinct from those observed in purified $\mathrm{CD}^{+} \mathrm{T}$ cell subsets obtained from naïve animals, and were intermediate to expression profiles of purified central memory and effector memory T cells. Expression of transcription factors elicited by SIV $\Delta$ nef vaccination also varied over time: cells obtained at later time points, temporally associated with greater protection, appeared more central-memory like than cells obtained at earlier time points, which appeared more effector memory-like. Expression of transcription factors associated with effector differentiation, such as ID2 and $R U N X 3$, were decreased over time, while expression of transcription factors associated with quiescence or memory differentiation, such as TCF7, BCOR and EOMES, increased. $\mathrm{CD}^{+} \mathrm{T}$ cells specific for a more conserved epitope expressed higher levels of TBX21 and $B A T F$, and appeared more effector-like than cells specific for an escaped epitope, consistent with continued activation by replicating vaccine virus. These data suggest transcription 
factor expression profiling is a novel method that can provide additional data complementary to the analysis of memory cell differentiation based on classical phenotypic markers. Additionally, these data support the hypothesis that ongoing stimulation by SIV $\Delta$ nef promotes a distinct protective balance of $\mathrm{CD} 8^{+} \mathrm{T}$ cell differentiation and activation states.

\section{Author Summary}

The live attenuated vaccine SIV $\Delta$ nef can induce robust $\mathrm{CD} 8^{+} \mathrm{T}$ cell- mediated protection against infection with pathogenic SIV in macaques. Thus, there is substantial interest in characterizing these immune responses to inform HIV vaccine design. Animals challenged at $15-20$ weeks post vaccination exhibit robust protection, whereas animals challenged at 5 weeks post-vaccination manifest little protection. Since the frequency of SIV-specific T cells decreases from week 5 to week 20 , it is likely that the quality of the response to challenge changes as virus-specific cells differentiate. We applied a novel approach of transcription factor expression profiling to characterize the differences in SIV-specific cell function and phenotype at more protected and less protected time points. Using unsupervised clustering methods informed by expression profiles assessed in purified $\mathrm{CD} 8^{+} \mathrm{T}$ cell subsets, we show that SIV-specific cells display expression profiles different than any purified $\mathrm{CD} 8^{+} \mathrm{T}$ cell subset, and intermediate to sorted effector memory and central memory subsets. SIV-specific cells overall appear more effector memory-like at week 5 postvaccination, and more central memory-like at week 20 post-vaccination. Distinct profiles of $\mathrm{CD}^{+} \mathrm{T}$ cells specific for different SIV epitopes having different immune escape kinetics suggests maturation is regulated by ongoing low-level replication of vaccine virus.

\section{Introduction}

Vaccination of rhesus macaques with SIV $\Delta$ nef can induce robust immune responses and can protect the majority of vaccinated animals from challenge with wild-type SIV virus strains [1-3]. To date, SIV $\Delta$ nef is the most efficacious of all vaccine strategies analyzed in the macaque model. Although safety concerns preclude the use of attenuated HIV as a human vaccine $[4,5]$, understanding the biological basis for immune protection conferred by SIV $\Delta$ nef may provide information important for the design of safe and efficacious HIV vaccines. Therefore, substantial efforts have been made to identify correlates of immune protection induced by SIV $\Delta$ nef over the last two decades.

Correlates of immune protection induced by SIV $\Delta$ nef and related attenuated SIV vaccines identified to date include both cellular and humoral adaptive immune responses [3,6-10]. $\mathrm{CD} 8^{+} \mathrm{T}$ cell responses in particular appear to be critical for SIV $\Delta$ nef-mediated protection. SIV $\Delta$ nef can induce robust $C D 8^{+}$CTL responses and protection can occur in the absence of neutralizing antibody responses [3,7]. Additionally, $\mathrm{CD} 8^{+}$cell depletion following vaccination with attenuated SIV vaccines results in impaired control of challenge virus [6,11]. Although the vaccine virus is rapidly cleared to levels in plasma that are at or below detection following vaccination in the majority of animals [1], virus continues to replicate at low levels [12,13]. Substantial evidence suggests that the replicative capacity of SIV $\Delta$ nef, and the ability to provide persistent low-level antigenic stimulation, may mediate the high efficacy of protection [3,1214]. A comparison of SIV $\Delta$ nef with more-attenuated SIV virus strains found a positive correlation of the magnitude of lymph-node resident SIV-specific $\mathrm{T}$ cells to protection from 
intravenous challenge [13]. However, SIV $\Delta$ nef does not induce greater numbers of SIV-specific $\mathrm{CD}^{+} \mathrm{T}$ cells than other vaccine approaches that do not induce protection [15-17]. Additionally, the frequency of SIV $\Delta$ nef-induced SIV-specific $\mathrm{CD}^{+} \mathrm{T}$ cells located in lymphoid and genital tissues does not correlate with the maturation of protection in this model [12]. The frequency or magnitude, therefore, of virus-specific precursors in blood and tissues may be less important for immune control than the composition of $\mathrm{CD} 8{ }^{+} \mathrm{T}$ cell memory phenotypes induced by SIV $\Delta$ nef. Immune protection takes approximately 15-20 weeks to develop following vaccination [18] and during that time, SIV-specific T cells acquire a more central memory-like phenotype but maintain elevated PD-1 expression [14]. Persistent expression of PD-1 on SIVspecific $\mathrm{CD}^{+} \mathrm{T}$ cells requires ongoing low-level viral replication, as $\mathrm{PD}-1$ expression is down regulated on cells specific for an epitope that undergoes escape [14]. These data, in conjunction with evidence of viral evolution following vaccination [1,19-21] and evidence that ongoing replication is required for vaccine efficacy, suggest that continued stimulation from viral epitopes present due to ongoing low-level replication of vaccine virus may induce a unique differentiation or activation state of SIV-specific $\mathrm{CD} 8^{+} \mathrm{T}$ cells. SIV $\Delta$ nef may also promote a balance or distribution of central memory and effector cells, or a $\mathrm{T}$ cell repertoire different than that induced by less protective vaccines. A complete understanding of how SIV $\Delta$ nef-induced $\mathrm{CD} 8^{+} \mathrm{T}$ cells mediate protection, and the relationship between $\mathrm{CD} 8^{+} \mathrm{T}$ cell differentiation stage and protective immunity remains unclear. Novel experimental methods that can provide additional information to what can be acquired with traditional approaches such as polychromatic flow cytometry may facilitate a more complete characterization of immune protection.

In the past decade, substantial progress has been made in characterizing the differentiation of $\mathrm{CD}^{+}$effector and memory cell subsets following antigenic stimulation [22]. Genetic approaches have demonstrated the importance of a number of individual transcription factors in regulating differentiation. However, the combinatorial expression of lineage-specific and general transcription factors and their aggregation at cis-regulatory elements dictate the expression of any specific gene and ultimately the phenotype of the cell [23-25]. Recognition of the combinatorial nature of transcription factor function has motivated a more holistic approach to understanding transcription factor function and prompted a number of comprehensive systems based descriptions of differential transcription factor usage and networks of transcriptional control in different tissues and cell lineages including the hematopoietic system [23,24,26,27].

To expand on the current capacity for cell phenotypic and functional analyses provided by methods such as polychromatic flow cytometry, we developed a novel approach that exploits the fundamental regulation of cell phenotype and function by combinatorial transcription factor activity. We reasoned that simultaneous expression profiling of multiple transcription factors known to regulate cell differentiation could facilitate discrimination of cell lineage and provide novel information complementary to other methods. To assess the utility of transcription factor expression profiling for the characterization of $\mathrm{CD}^{+} \mathrm{T}$ cell differentiation, we measured the expression of a panel of transcription factors known to regulate $\mathrm{T}$ cell differentiation in sorted bulk populations of naïve and memory $\mathrm{CD}^{+} \mathrm{T}$ cells and in SIV-specific cells induced by SIV $\Delta$ nef vaccination. Subsequent organization of samples by unsupervised clustering of expression data indicates that transcription factor expression profiling is a sensitive method that can clearly identify cells at different stages of $\mathrm{CD}^{+} \mathrm{T}$ cell differentiation. We subsequently applied this method to further characterize the differentiation of $\mathrm{CD}^{+} \mathrm{T}$ cells induced by SIV $\Delta$ nef, and to characterize the phenotype of $\mathrm{CD}^{+} \mathrm{T}$ cells temporally associated with either protective, or non-protective immune responses. Our data demonstrate the utility of transcription factor expression profiling to characterize the differentiation of $\mathrm{CD}^{+} \mathrm{T}$ cells following SIV $\Delta$ nef vaccination, and indicate that SIV-specific $\mathrm{CD} 8^{+} \mathrm{T}$ cells appear to be transcriptionally intermediate to, yet clearly distinct from, purified effector memory and central memory $\mathrm{T}$ cells 
isolated from vaccine-naïve animals. Taken together, our results support the conclusion that ongoing activation of $\mathrm{CD} 8^{+} \mathrm{T}$ cells by replicating vaccine virus may induce populations of $\mathrm{CD}^{+} \mathrm{T}$ cells possessing phenotypic characteristics distinct from, but with similarities to, classically defined effector memory and central memory cells.

\section{Results}

\section{Transcription factors selected for expression profiling}

To examine whether expression profiling of multiple transcription factors would facilitate discrimination of different $\mathrm{CD} 8^{+} \mathrm{T}$ cell differentiation states, we initially selected a panel of 18 transcription factors to analyze (Table 1) based on published data indicating their involvement in the regulation of $\mathrm{CD} 8^{+} \mathrm{T}$ cell differentiation or function. A subset of these transcription factors, such as T-bet, Eomes, Blimp- 1 and Id 2 are well-characterized primary regulators of CD8 ${ }^{+}$ memory or effector cell differentiation [28-36]. Another set of transcription factors, including BATF, Runx3 and BCL11b, regulate expression of the transcription factors noted above that

Table 1. Transcription factors analyzed in bulk and SIV-specific CD8 ${ }^{+} \mathrm{T}$ cells.

\begin{tabular}{|c|c|c|}
\hline $\begin{array}{l}\text { Gene } \\
\text { Symbol }\end{array}$ & $\begin{array}{l}\text { Transcription } \\
\text { Factor }\end{array}$ & Function \\
\hline PRDM1 & Blimp-1 & $\begin{array}{l}\text { Represses IL-2 expression, Bcl-6 antagonist, promotes effector } \\
\text { differentiation }[32,33]\end{array}$ \\
\hline TBX21 & T-bet & Promotes CD8 effector differentiation $[28,29]$ \\
\hline EOMES & Eomesodermin & $\begin{array}{l}\text { Required for early CD8 effector function and subsequent memory CD8 } \\
\text { differentiation }[30,31]\end{array}$ \\
\hline$B C L 6$ & Bcl-6 & $\begin{array}{l}\text { Induces central memory differentiation, functions reciprocally to Blimp- } \\
1[55,61]\end{array}$ \\
\hline$B C O R$ & BCoR & Bcl-6 corepressor [54] \\
\hline TCF7 & Tcf-7 (Tcf-1) & $\begin{array}{l}\text { Wnt effector, promotes quiescence, downregulated with antigen } \\
\text { stimulation, promotes Eomes expression }[44,45]\end{array}$ \\
\hline LEF1 & Lef-1 & $\begin{array}{l}\text { Wnt effector, promotes quiescence, downregulated with antigen } \\
\text { stimulation [44] }\end{array}$ \\
\hline$R O R C$ & Roryt & $\begin{array}{l}\text { Represses IFNy expression, functions as transcriptional repressor in } \\
\text { naïve or memory CD8 T cells }[46,49]\end{array}$ \\
\hline$A H R$ & AHR & $\begin{array}{l}\text { Regulates lymphoid tissue inducing function of innate lymphoid cells } \\
{[84,85]}\end{array}$ \\
\hline$R O R A$ & Rora & Promotes effector responses in activated CD8 cells [46] \\
\hline BATF & BATF & $\begin{array}{l}\text { Upregulated by PD-1 signaling, promotes Roryt and T-bet expression, } \\
\text { regulates effector differentiation; upregulated in exhausted CD8 cells } \\
\text { [37-39] }\end{array}$ \\
\hline PBXЗ & PBX3 & $\begin{array}{l}\text { Mediates locus accessibility, upregulated in exhausted CD8 cells } \\
{[86,87]}\end{array}$ \\
\hline$B C L 11 B$ & $\mathrm{BCL} 11 \mathrm{~b}$ & $\begin{array}{l}\text { Regulates Runx3 and FoxP3, promotes cytolytic effector function } \\
\text { [41-43] }\end{array}$ \\
\hline RUNX3 & Runx3 & $\begin{array}{l}\text { Promotes expression of T-bet and Eomes, IFNy, perforin, granzyme B } \\
\text { [40] }\end{array}$ \\
\hline GATA3 & GATA3 & Required for sustained TCR-mediated signaling and CTL activity [48] \\
\hline ID2 & Id2 & Promotes CD8 effector memory differentiation [34-36] \\
\hline IRF4 & IRF4 & $\begin{array}{l}\text { Induced by antigen receptor signaling, represses Eomes, promotes } \\
\text { Blimp-1 expression; cooperatively regulates effector differentiation with } \\
\text { BATF }[39,56,88,89]\end{array}$ \\
\hline NFIL3 & NFIL3 & $\begin{array}{l}\text { Activates IL-3 promoter, essential for intraepithelial lymphocyte } \\
\text { development }[90,91]\end{array}$ \\
\hline
\end{tabular}

doi:10.1371/journal.ppat.1004740.t001 
serve as regulators of $\mathrm{T}$ cell function [37-43]. A third group, the Wnt signaling pathway effector transcription factors Lef- 1 and Tcf-7 (also known as Tcf-1), are positive regulators of quiescence $[44,45]$. A fourth set of transcription factors, Ror $\alpha$, Roryt and GATA3, regulate differentiation of additional $\mathrm{T}$ cell lineages and $\mathrm{CD} 8^{+} \mathrm{T}$ cell activation and effector function [46-49].

\section{Transcription factors are differentially expressed in sorted $\mathrm{CD} 8^{+} \mathrm{T}$ cell subsets}

To determine if transcription factor expression profiling can be used to identify distinct stages of $\mathrm{CD}^{+} \mathrm{T}$ cell differentiation, we initially sorted highly purified populations of naïve, central memory, transitional memory, and effector memory $\mathrm{CD}^{+} \mathrm{T}$ cells from five healthy unvaccinated uninfected rhesus macaques based on differential surface expression of CD28, CD95 and CCR7 (S1 Fig., Fig. 1). We then measured the expression of the transcription factors included in our panel by multi-target qPCR, and used agglomerative unsupervised hierarchical clustering of the expression data to organize the samples. The sample dendrogram (Fig. 1) demonstrates clear segregation of samples by cell differentiation stage, with the three memory $\mathrm{CD} 8^{+}$ T cell subsets segregating from naïve cells.

Distinct sets of transcription factors displayed unique expression profiles among cell subsets (Fig. 2). The Wnt pathway effectors $L E F 1$ and TCF were expressed at the highest levels in naïve and central memory cells, and lower levels in transitional and effector memory cells. The transcription factors TBX21, PRDM1 and NFIL3, were expressed at the highest levels in effector memory cells. In contrast, EOMES, $A H R$ and $R O R C$, were expressed at the highest level in transitional memory cells.

All of the transcription factors except IRF4 and BCL11B were expressed differentially among the $\mathrm{CD}^{+} \mathrm{T}$ cell subsets $(\mathrm{p} \leq 0.001)$. The differences in expression levels varied widely among transcription factors with some transcription factors demonstrating up to 1000 -fold differences in mean expression level between sorted cell populations.

Unsupervised clustering of samples by differentiation stage demonstrates that expression profiling of transcription factors is a sensitive method that can be used to clearly resolve distinct stages of memory $\mathrm{CD} 8^{+} \mathrm{T}$ cell differentiation.

\section{SIV-specific CD8 ${ }^{+} \mathrm{T}$ cells isolated at week 5 or week 20 post-vaccination with SIV $\Delta$ nef have distinct expression profiles}

Longitudinal studies suggest that vaccine-induced protection to pathogenic virus challenge matures during the weeks following vaccination $[2,11,18,50]$. Animals challenged at 15 to 20 weeks following vaccination are better protected than animals challenged at five weeks following vaccination. As transcription factor expression profiling was able to differentiate between sorted naïve and memory $\mathrm{T}$ cell subsets, we sought to use this approach to identify differences in transcription factor usage in SIV-specific $\mathrm{CD}^{+} \mathrm{T}$ cells isolated at time points following $\mathrm{SIV} \Delta$ nef vaccination associated with either lesser or greater protection, and to further characterize the phenotype of these cells by comparing their transcription factor expression profiles with the profiles of sorted naïve and memory $\mathrm{CD} 8^{+} \mathrm{T}$ cell subsets. We analyzed $\mathrm{CD} 8^{+} \mathrm{T}$ cells specific for either of two Mamu-A*01-restricted immunodominant SIV epitopes differing in their propensity for immune escape. The Gag CM9 epitope is typically conserved over time [51], whereas the Tat SL8 epitope mutates rapidly following infection in response to immune pressure, beginning to accumulate sequence heterogeneity at two weeks post infection [52,53]. We hypothesized that the distinct escape kinetics and resulting sensitivities to ongoing antigenic stimulation would induce differences in differentiation stage resolvable by transcription 


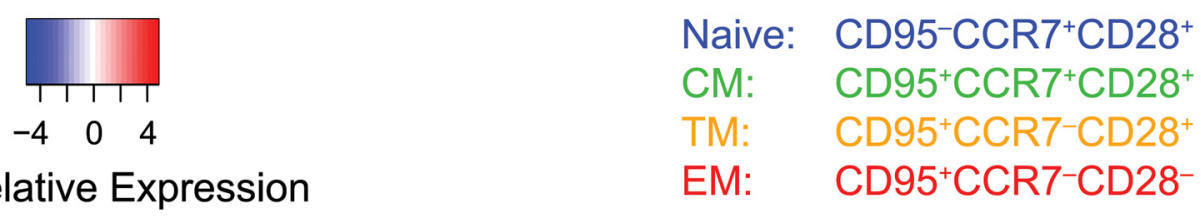

$\log _{2}$ Relative Expression

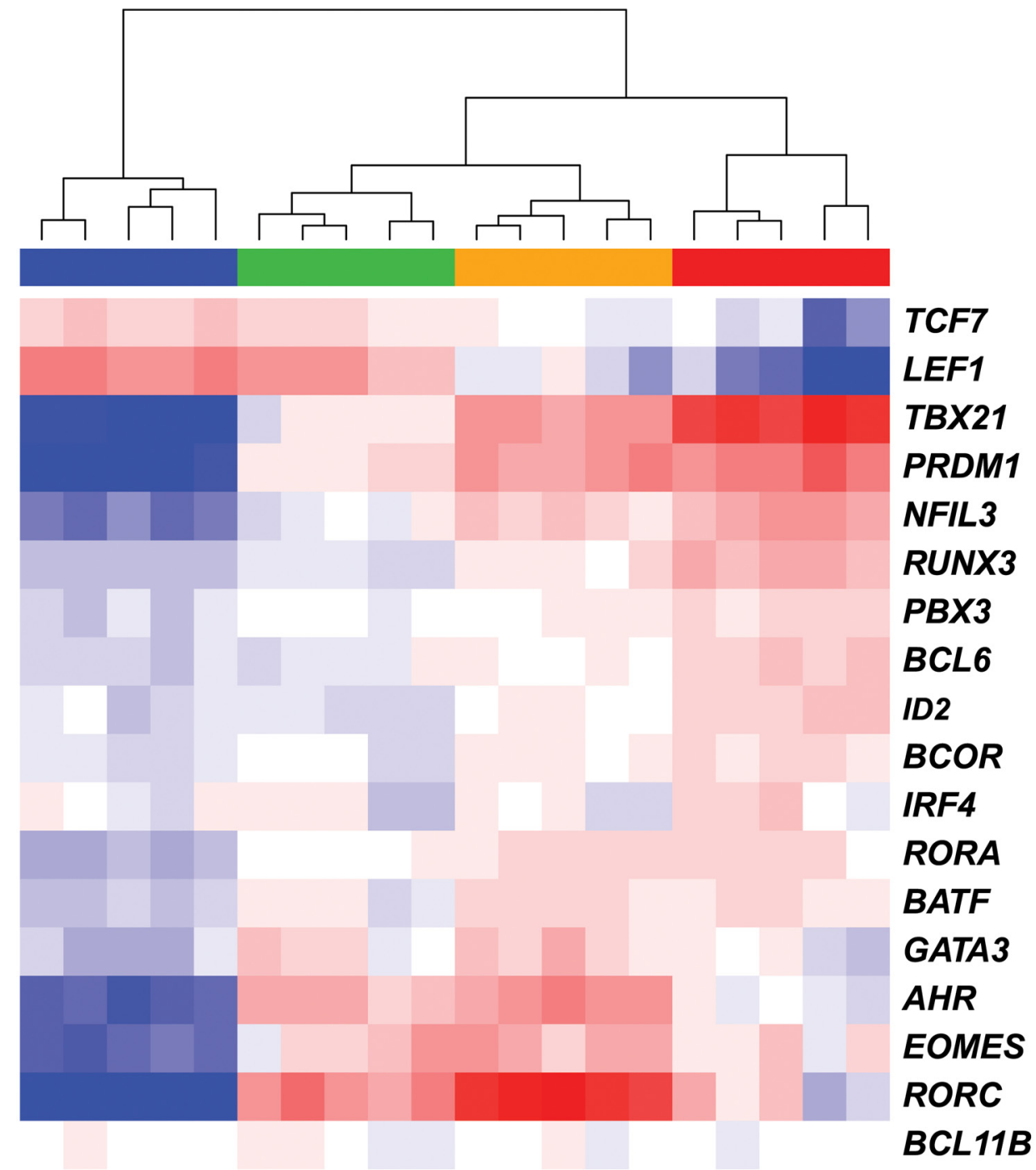

Fig 1. Segregation of sorted CD8 ${ }^{+} \mathrm{T}$ cell subsets by unsupervised hierarchical clustering. Heat map expression values were transcript mean centered and represent expression relative to endogenous controls. Hierarchical clustering was performed using Euclidean distance and complete linkage methods.

doi:10.1371/journal.ppat.1004740.g001

factor expression profiling. We sorted Gag CM9- and Tat SL8- specific CD8 ${ }^{+} \mathrm{T}$ cells obtained from four rhesus macaques at either 5 weeks or 20 weeks following SIV $\Delta$ nef vaccination, and measured the expression levels of the transcription factors in our target panel by multi-target qPCR.

To integrate the expression profiles of the SIV-specific cells with the sorted $\mathrm{CD} 8^{+}$subsets, we applied principal component analysis (PCA) to the combined data sets. Plotting principal components 1 vs, 2, and principal components 2 vs. 3, (PC1, PC2, PC3; Fig. 3A, S1 Video) segregated the data into distinct clusters. The data points representing the sorted $\mathrm{CD} 8^{+} \mathrm{T}$ cells 

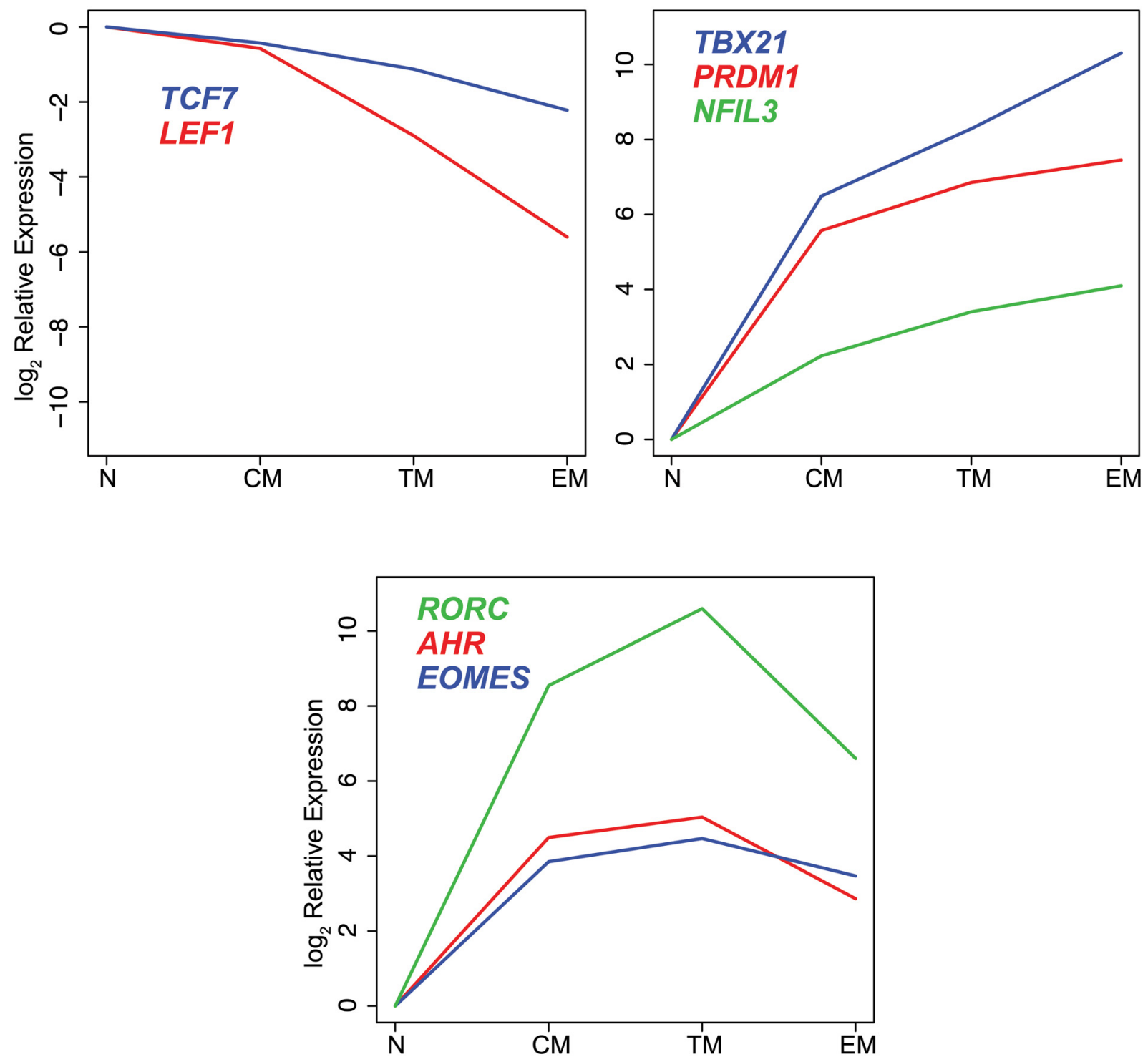

Fig 2. Differential expression of transcription factors in $\mathrm{CD8}^{+}$naïve and memory $\mathrm{T}$ cell subsets. $\log _{2}$ mean expression values were normalized to naïve cell samples.

doi:10.1371/journal.ppat.1004740.g002

occupy the periphery of the PC1 vs. PC2 plot, and segregate into separate clusters based upon cell differentiation stage. The naïve cells segregate from the memory cells along the PC1 axis, whereas the memory cells segregate along the PC2 axis, with the transitional memory cells positioned intermediately between the central and effector cells. The PC1 and PC2 loading factors (Fig. 3B) indicate that in this analysis, differential expression of LEF1, TCF7, PRDM1 and $T B X 21$ strongly influence segregation of naïve from memory cells, whereas differential expression of ID2, RUNX3, AHR and LEF1 strongly influence segregation of memory cell subsets. The SIV-specific CD8 ${ }^{+}$T cells cluster with the sorted memory cells on the PC1 axis, and are positioned intermediately between central memory and effector memory cells on the PC2 axis. This intermediate position on the PC2 axis in part reflects the combined expression profiles of different memory subsets present in the SIV-specific cell samples. However, the SIV-specific 
A
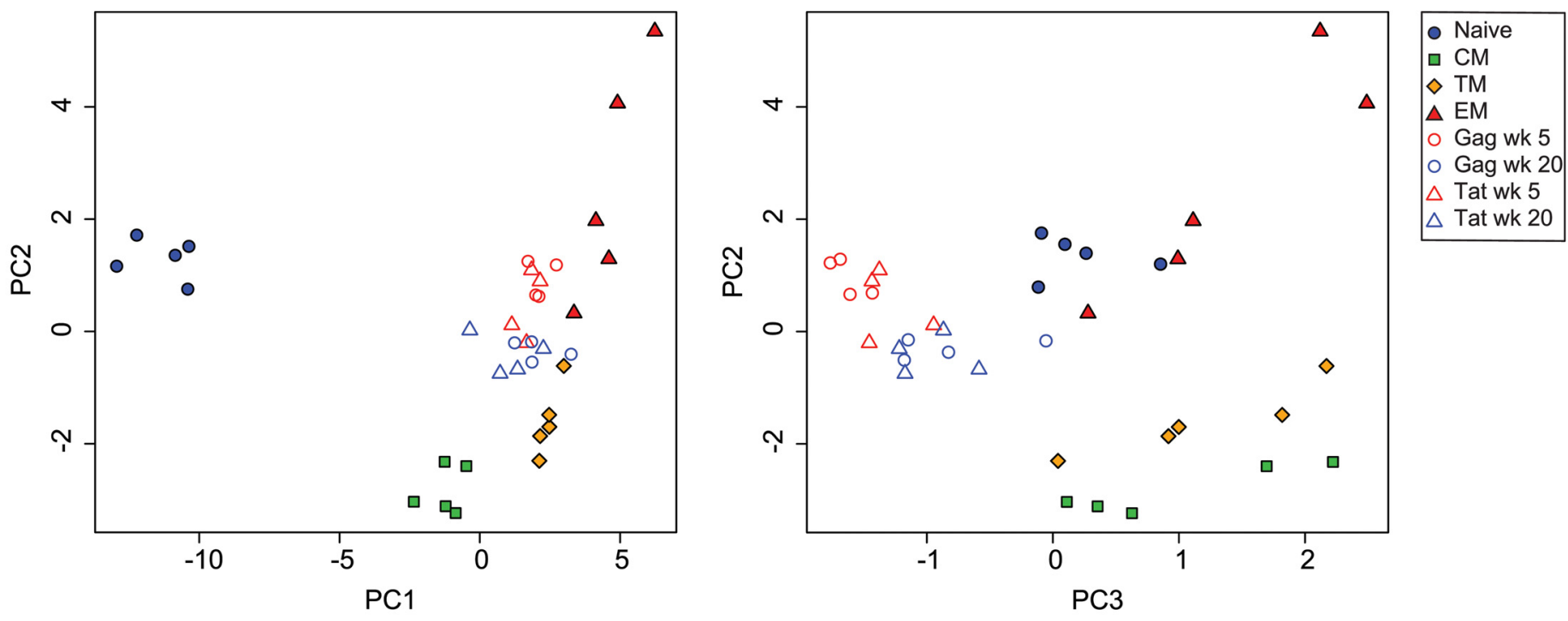

B
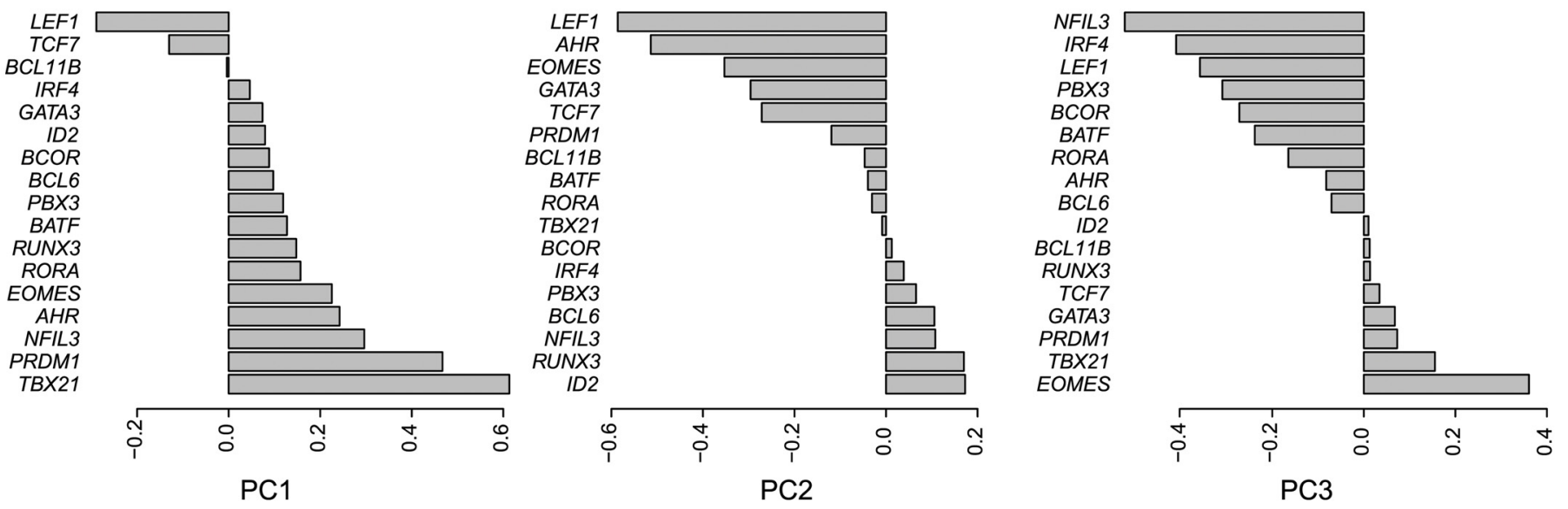

Fig 3. Principal component analysis of transcription factor expression profiles from SIV-specific MHC tetramer-sorted CD8 ${ }^{+} \mathrm{T}_{\text {cells }}$ and sorted CD8 $^{+}$T cell subsets. (A) Plot of principal components 1 vs. 2, and 2 vs. 3 for each of the expression profiles assessed in sorted naïve and memory CD8 ${ }^{+} T$ cell subsets isolated from healthy control animals $(n=5)$, and SIV-specific MHC tetramer-sorted CD8 ${ }^{+}$T cells isolated from animals $(n=4)$ at week 5 or week 20 following SIV $\Delta$ nef vaccination. Principal components 1, 2 and 3 explain $92 \%$ of cumulative total variance. (B) PCA loading factors for each transcription factor.

doi:10.1371/journal.ppat.1004740.g003

samples significantly segregate from any sorted memory subset, particularly on the PC 3 axis $(\mathrm{p}<0.001)$, indicating that the transcription factor expression profiles of the SIV-specific cells are distinct from the sorted subsets and are not solely comprised of proportions of memory subsets. The PC3 loading factors (Fig. 3B) indicate that in this analysis, the differential expression of NFIL3, IRF4, LEF1 and EOMES influence segregation of SIV-specific cells from the sorted naïve and memory subsets. The SIV-specific cells form two clusters, generally organized by week post-infection. The week 5 and week 20 post-vaccination samples occupy significantly different positions in PCA space $(\mathrm{p}<0.01)$. The week 5 post-vaccination cells, temporally associated with less protection to challenge, have greater PC2 values, indicating a more effector-like 
profile, whereas the week 20 post-vaccination cells have lesser PC2 values indicating a more central-memory like profile. The samples also significantly segregate based on epitope specificity $(\mathrm{p}<0.01)$. The Gag CM9-specific cells have overall higher PC2 values indicating a more effector-like phenotype, whereas the Tat SL8-specific cells have lower PC2 values indicating a more central memory-like phenotype. The changes in expression profiles from week 5 to week 20 are consistent with SIV-specific $\mathrm{CD} 8^{+} \mathrm{T}$ cells becoming overall more central memory-like and less effector-like over time following vaccination. Similarly, the differences seen between Gag CM9- and Tat SL8-specific cells are consistent with the kinetics of epitope escape and likely reflect the loss of antigen stimulation of the Tat-specific cells versus the ongoing stimulation of the Gag-specific cells.

To further validate the approach of using transcription factor expression profiling to characterize cell differentiation, we compared this method to conventional flow-cytometric assessment of $\mathrm{CD} 8^{+} \mathrm{T}$ cell memory subsets present in SIV-specific populations at different time points following vaccination. In agreement with our expression profiling methods, flow cytometric methods based on differential expression of CCR7 and CD28 showed an overall increase in CM cells and a decrease in EM cells from week 5 to week 20 post-vaccination. Furthermore, Tat SL8-specific cells had greater frequencies of CM cells and lesser frequencies of EM cells than Gag CM9-specific cells (S2A Fig.). Additionally, the ratio of EM to CM cells found in a sample of SIV-specific cells positively correlates with the PC2 value of the combined PCA analysis (S2B Fig.).

To provide additional context for interpreting SIV-specific $\mathrm{CD} 8{ }^{+} \mathrm{T}$ cell expression profiles, and to further examine the effect of ongoing viral replication on transcription factor expression profiles, we used PCA to compare vaccine-specific and sorted naïve and memory subsets to SIV-specific $\mathrm{CD}^{+} \mathrm{T}$ cells collected at week 20 following infection with pathogenic wild-type SIV.

A plot of principal components 1 and 2 (Fig. 4) positioned Gag CM9-specific cells obtained from wild-type SIV-infected animals near the sorted effector memory cells but with higher PC2 values. Tat SL8-specific cells from wild-type SIV-infected animals were more heterogeneous but generally occupied positions more positive along the PC2 axis than SIV $\Delta$ nef-induced cells, with PC2 values similar to sorted effector memory cells. These results are consistent with the idea that ongoing activation by replicating virus may induce a more effector-like phenotype, and that epitope escape facilitates a more central memory-like phenotype.

A number of individual transcription factors were significantly differentially expressed between week 5 post-vaccination and week 20 post-vaccination (Fig. 5). For example BCOR, EOMES and TCF7 were expressed at significantly higher levels at week 20 post-vaccination. Higher expression of these transcription factors is consistent with a more quiescent and central memory-like phenotype $[44,45,54]$. Conversely, ID2, RORA, NFIL3 and RUNX3 were expressed at significantly lower levels at week 20 post-vaccination. Lower expression of ID2 and RUNX3 is also consistent with a more central memory-like phenotype [35,40]. Elevated TBX21 expression, which is associated with effector differentiation, however, was maintained at week 20, consistent with continued effector function $[28,29]$.

A number of transcription factors were also significantly differentially expressed between Gag CM9- and Tat SL8- specific cells. Gag-specific $\mathrm{CD} 88^{+} \mathrm{T}$ cells expressed significantly higher levels of BATF, TBX21 and RORA. These differential expression profiles are consistent with Gag CM9-specific cells maintaining a more effector-like phenotype than Tat SL8-specific cells $[28,37,46]$. Interestingly, EOMES was expressed at significantly lower levels in Gag CM9specific cells than in Tat SL8-specific cells at week 5 post-vaccination, and a trend towards higher expression was observed in Gag CM9-specific cells than in Tat SL8-specific cells at week 20 post-vaccination. Conversely, ID2 is expressed at significantly higher levels at week 5 in 


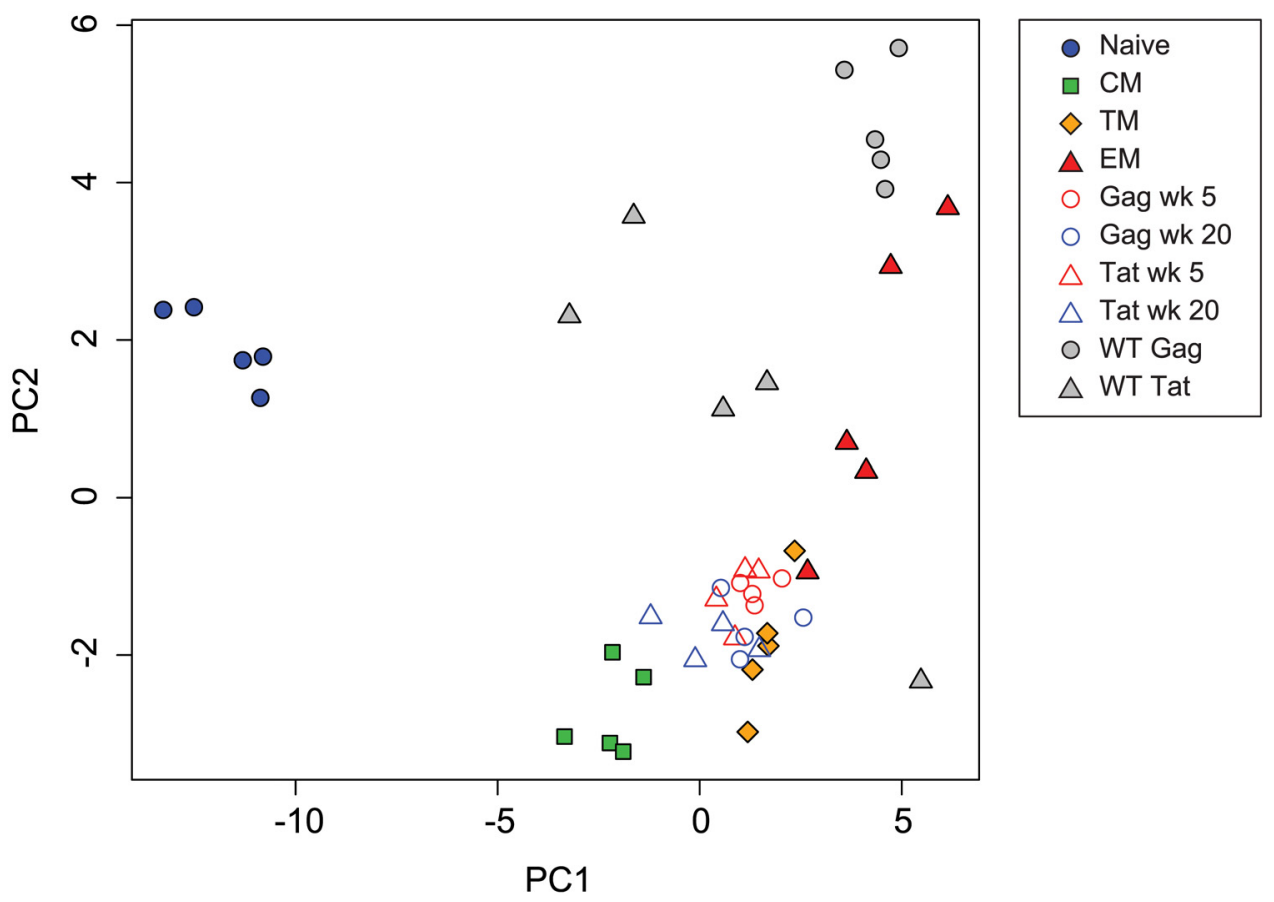

Fig 4. Principal component analysis of transcription factor expression profiles from SIV-specific MHC tetramer-sorted $\mathrm{CD}^{+} \mathrm{T}$ cells from animals vaccinated with SIV $\Delta$ nef, animals infected with wild-type SIV, and sorted CD8 ${ }^{+} \mathrm{T}$ cell subsets. Plot of principal components 1 and 2 for each of the expression profiles assessed from sorted naïve and memory $\mathrm{CD}^{+} \mathrm{T}$ cell subsets, SIV-specific MHC tetramer-sorted $\mathrm{CD}^{+} \mathrm{T}$ cells isolated from SIV $\Delta$ nef-vaccinated animals, and $\mathrm{MHC}$ tetramer-sorted CD8 ${ }^{+} \mathrm{T}$ cells isolated from animals $(n=5)$ at 20 weeks following wild-type SIV infection. Principal components 1 and 2 explain 77 percent of cumulative total variance.

doi:10.1371/journal.ppat.1004740.g004

Gag-specific cells and more similar to Tat-specific cells at week 20. These trends are consistent with Tat-specific cells being more central memory-like even at the earlier time point $[31,35]$.

Many of the transcription factors were differentially expressed between SIV-specific CD8 ${ }^{+}$ T cells in wild-type SIV- and SIV $\Delta$ nef-infected animals at week 20 post-vaccination, likely reflecting the higher viral loads and attendant greater stimulation of SIV-specific cells in animals infected with wild-type SIV. EOMES, ID2 and RUNX3 were expressed at significantly higher levels in cells from wild-type SIV-infected animals ( $\mathrm{p} \leq 0.05)$. In contrast, $A H R$ and $L E F 1$ were expressed at significantly lower levels in wild-type SIV-specific cells. A number of transcription factors were differentially expressed between Gag- and Tat-specific cells in wild-type SIV-infected animals. In particular, the Wnt pathway effectors TCF7 and $L E F 1$, as well as BCL6, had significantly higher expression in Tat-specific cells. In contrast, EOMES, RUNX3 and IRF4 demonstrated trends towards higher expression in Gag-specific cells. These differences are consistent with the different kinetics of epitope escape, and consistent with loss of antigen stimulation mediating cell differentiation towards a less activated or more central memory phenotype $[11,12,44,55,56]$.

Overall, the differences we observed in transcription factor expression profiles suggest that the process of $\mathrm{CD}^{+} \mathrm{T}$ cell differentiation following SIV $\Delta$ nef vaccination involves the coordinate regulation of multiple transcription factors. At later time points following vaccination, SIV-specific cells express higher levels of transcription factors associated with memory differentiation, such as EOMES and TCF7, down-regulate transcription factors associated with effector responses such as ID2 and RUNX3, yet maintain elevated levels of TBX21. 


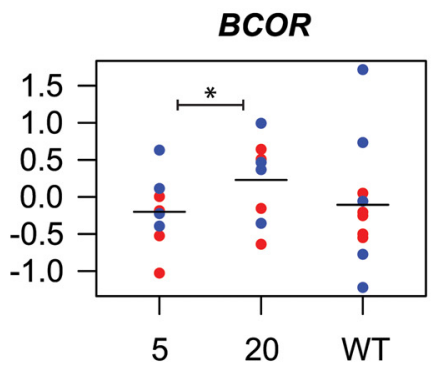

ID2
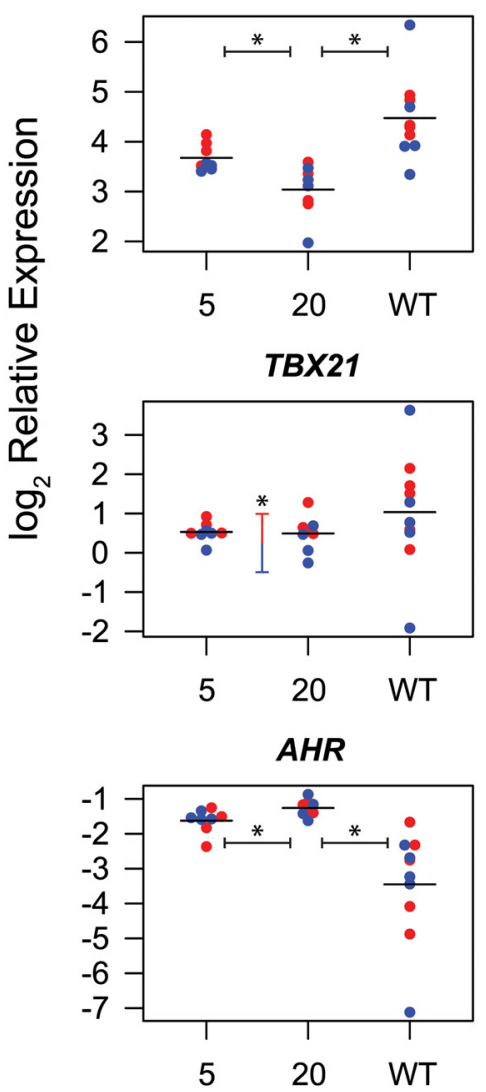

EOMES

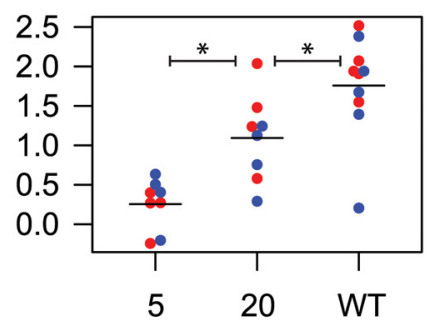

RORA

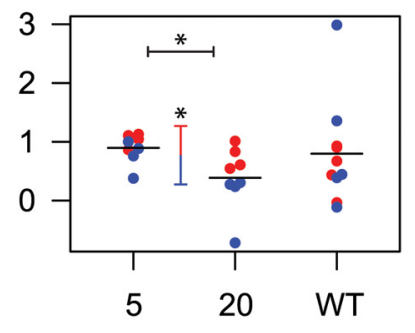

BATF

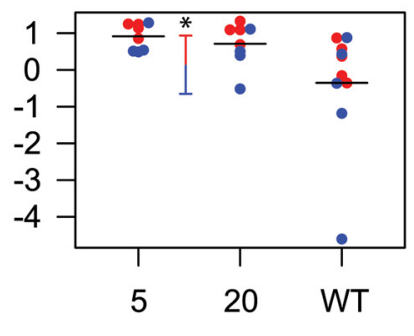

BCL6

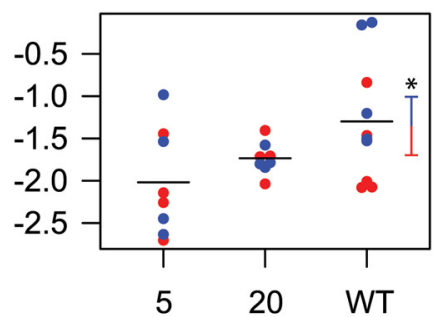

TCF7

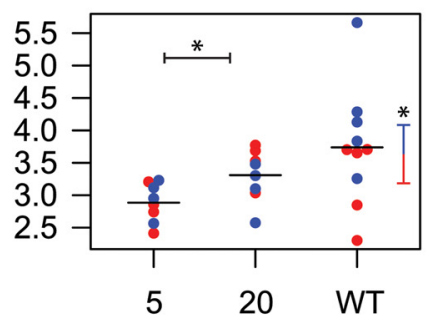

NFIL3

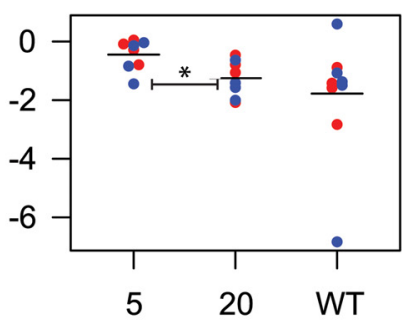

LEF1

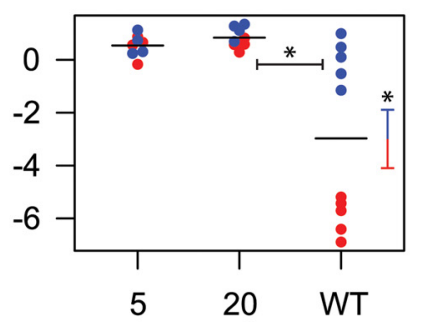

GATA3

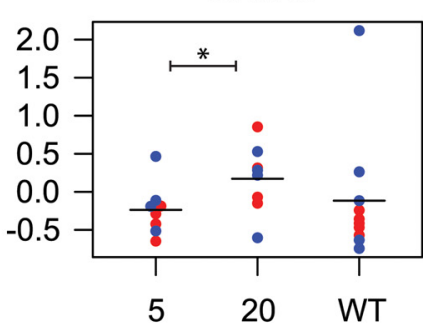

RUNX3

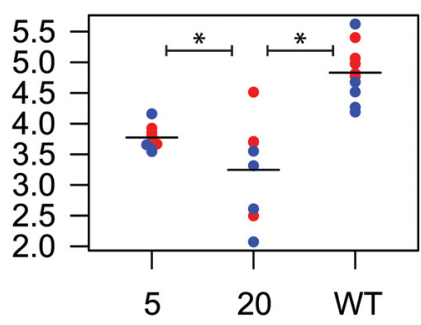

IRF4

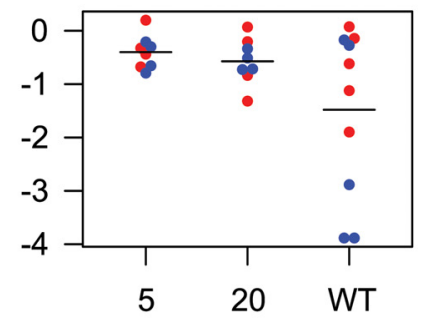

Fig 5. Differential expression of transcription factors in $\mathrm{CD8}^{+} \mathrm{T}$ cells isolated at week 5 and week 20 post-vaccination with SIV $\Delta$ nef and at week 20 post-infection with wild-type SIV. Symbols indicate $\log _{2}$ expression relative to endogenous controls in cells from individual animals. Red symbols indicate Gag CM9-specific cells, blue symbols indicate Tat SL8-specific cells. Sample means are indicated by horizontal bars. Statistically significant ( $\mathbf{0} \leq 0.05)$ differences in transcription factor expression between cells from week 5 and week 20 post-SIV $\Delta$ nef vaccination, or between cells from week 20 post-SIV $\Delta$ nef vaccination and week 20 post-wild-type SIV infection are indicated by horizontal bars with asterisks. Statistically significant differences between Gag CM9 and Tat SL8-specific cells are indicated by vertical bars with asterisks.

doi:10.1371/journal.ppat.1004740.g005

To facilitate comparison of expression levels of individual transcription factors in the different populations of T cells, we also generated a PCA heatmap (Fig. 6) of each transcription factor by overlaying expression values as heatmap colors on a plot of principal components 1 and 2 .

The PCA heatmaps demonstrate that expression of PRDM1 and TBX21 in SIV-specific cells is similar to central memory or transitional memory cells. In contrast, expression of EOMES, TCF7, GATA3 and BCL6 in SIV-specific cells is more similar to effector memory cells. Expression of $A H R, I D 2, R U N X 3$ and LEF1 in SIV-specific cells is intermediate between central memory and effector memory cells. Interestingly, expression of the transcription 

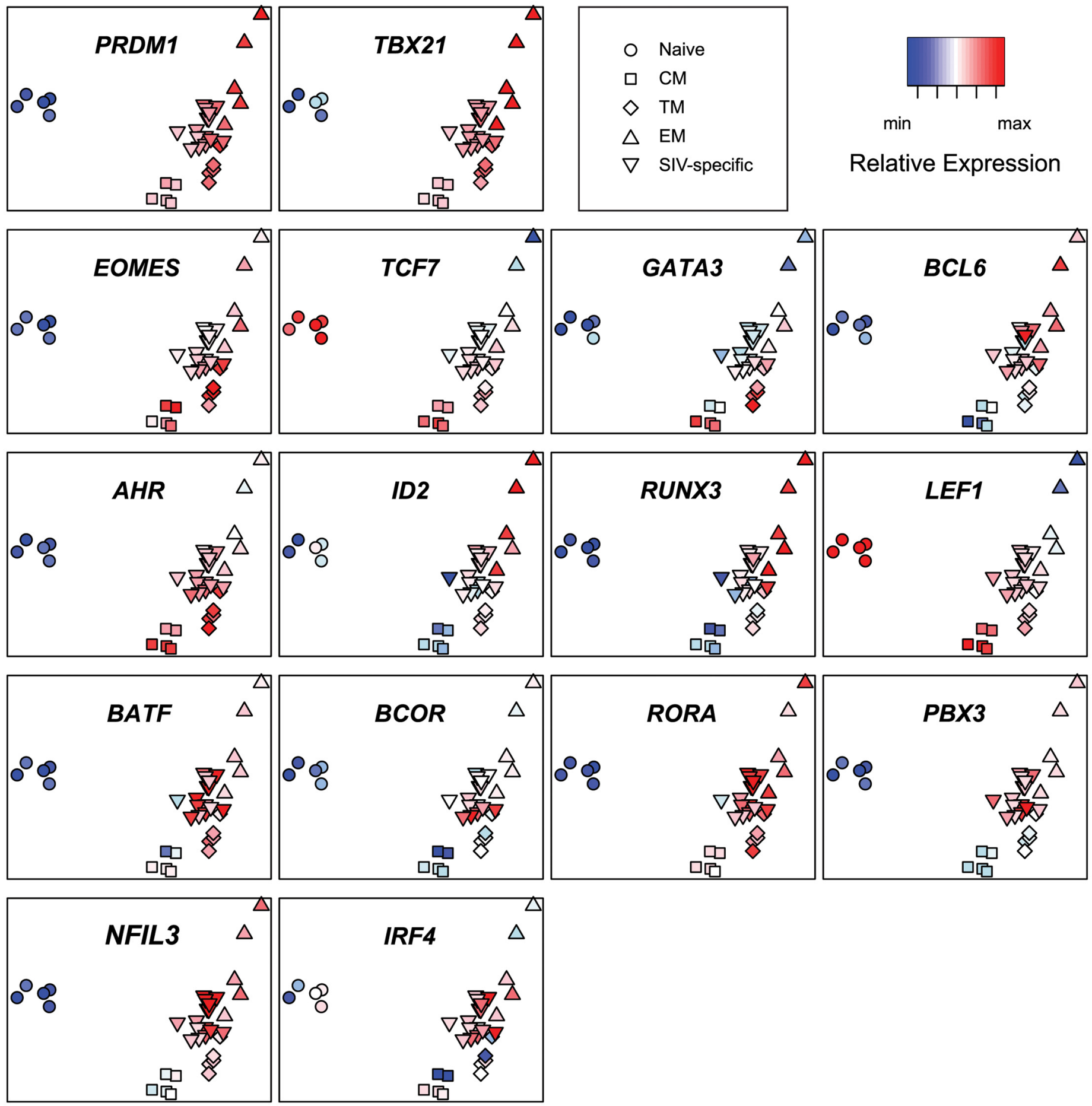

Fig 6. Principal component analysis heat maps of transcription factor expression profiles from SIV-specific MHC tetramer-sorted CD8 ${ }^{+} \mathrm{T}_{\text {cells }}$ from animals vaccinated with SIV $\Delta$ nef, and sorted naïve and memory $\mathbf{C D}^{+} \mathbf{T}$ cells. Heat $\operatorname{map} \log _{2}$ relative expression values were range normalized for each transcription factor.

doi:10.1371/journal.ppat.1004740.g006 
factors BATF, BCOR, RORA, NFIL3, IRF4 and PBX3 is greater in SIV-specific cells than any sorted subset. The higher expression levels of these transcription factors in SIV-specific cells provides additional evidence that the SIV-specific cells are transcriptionally distinct from any purified memory subset, or proportion of subsets. Although statistically significant for only $P B X 3(\mathrm{p}<0.05)$ these trends of increased expression may, in part, reflect ongoing stimulation from replicating virus.

\section{Discussion}

Memory $\mathrm{T}$ cells display substantial heterogeneity in phenotype, function and anatomic distribution [57]. The characterization of memory cell differentiation and the definition of phenotypic memory cell subpopulations has traditionally employed flow cytometric analyses of a subset of cell surface proteins, which regulate cell activation, survival and tissue-homing [58-60]. Over the past decade, the characterization of molecular mechanisms regulating memory differentiation has also identified key transcription factors that modulate the gene expression profiles in differentiating cells and cell subpopulations [22]. As transcription factors fundamentally regulate cell phenotype and function, global analyses of differential transcription factor usage accompanying cell differentiation can conceptually both identify novel subpopulations of cells not resolvable by standard flow cytometric techniques and provide novel insights into the process of cell differentiation and the function of cell subpopulations.

We validated this approach by initially characterizing the transcription factor expression profiles of $\mathrm{CD}^{+} \mathrm{T}$ cells isolated at different stages of $\mathrm{CD} 8^{+} \mathrm{T}$ cell differentiation, and we subsequently used these data to characterize $\mathrm{CD} 8^{+} \mathrm{T}$ cells induced by SIV $\Delta$ nef vaccination and wildtype SIV infection. Clustering analyses of transcription factor expression data verified that $\mathrm{CD}^{+} \mathrm{T}$ cells purified by traditional flow cytometric gating strategies display distinct transcription factor expression profiles. This strict segregation by differentiation state, of cells from all animals is striking, given that rhesus macaques are outbred animals and would be expected to display substantial transcriptional heterogeneity between individuals. The three memory subsets had transcription factor expression profiles more similar to each other than to naive cells, and the transitional memory cells appeared more similar to central memory cells than to effector memory cells. The expression profiles across subsets corroborates, for many of the transcription factors, patterns of expression that have been reported for single transcription factors or small subsets of transcription factors, although comprehensive analyses of expression of multiple transcription factors have not previously been undertaken. TBX21, PRDM1, RUNX3 and $I D 2$, for example, were expressed at higher levels in sorted effector memory cells, whereas the Wnt pathway effectors $L E F 1$ and TCF7 were expressed at higher levels in the more quiescent naive and central memory cells. The high ratio of TBX21 to EOMES observed in effector memory cells, and similarly, the high ratio of PRDM1 to BCL6 observed in transitional memory and effector memory cells is consistent with the promotion of an effector phenotype [61]. Given the caveat that differences in transcription do not always directly correlate with differences in protein expression or function, overall, these results validate the approach of using transcription factor expression profiling to define the memory differentiation state of $\mathrm{CD} 8^{+} \mathrm{T}$ cells.

We subsequently used transcription factor expression profiling to characterize changes in SIV-specific $\mathrm{CD}^{+} \mathrm{T}$ cells over time as immune protection to challenge matures following vaccination. Half of the transcription factors assessed had significantly different $(\mathrm{p} \leq 0.05)$ expression levels at week 20 than at week 5 post-vaccination, and segregation by PCA suggested that SIV-specific cells had substantially different expression profiles at the two time points. SIVspecific $\mathrm{CD}^{+} \mathrm{T}$ cells in SIV $\Delta$ nef-vaccinated animals at week 20 displayed a transcriptional signature characteristic of (but not identical to) central memory cells, as manifested by elevated 
levels of TCF7 and EOMES and decreased expression of ID2 and RUNX3. Importantly, because transcription was assessed in bulk populations of cells, differences between levels of expression, and location in PCA space reflect both differences between expression levels on a per-cell basis, and differences in proportions of subsets present in the sample. Thus, the more central memory-like expression profile displayed at week 20 post-vaccination likely reflects the greater proportion of central memory-like cells present at week 20 post-vaccination, in agreement with our conventional flow cytometric analyses, but may also reflect a more central-memory like profile in SIV-specific cells overall.

A number of transcription factors were also differentially expressed between cells with different epitope specificities and immune escape kinetics. For example, TBX21 and BATF were expressed at higher levels in Gag CM9-specific cells than in Tat SL8-specific cells. Since BATF is upregulated downstream of PD-1 signaling [38], this observation is consistent with the higher levels of PD-1 expressed on Gag CM9-specific cells than in Tat SL8-specific cells [14]. The role of PD-1 in promoting an exhausted T cell phenotype in the setting of chronic viral infection has been widely described $[62,63]$. However, the expression of PD-1 is not an indication in itself of an exhausted phenotype and more accurately reflects cell activation $[13,14,64]$. Overall, the Tat SL8-specific cells appeared less activated and more memory-like than the Gag CM9-specific cells. Although differences in expression profiles between Gag CM9- and Tat SL8-specific cells are likely to be influenced by a variety of variables, the differences we observed are consistent with the loss of antigenic stimulation due to the evolution of escape in the Tat SL8 epitope, and on-going stimulation of Gag CM9-specific cells. These results are also consistent with prior work demonstrating a decline in the frequency of activated Tat SL8-specific cells, but not Gag CM9-specific cells in genital tissue from 5 to 20 weeks postvaccination with SIV $\Delta$ nef [12].

SIV-specific cells from wild-type SIV-infected animals displayed a pattern of expression of transcription factors more characteristic of effector memory cells than SIV-specific cells from SIV $\Delta$ nef-vaccinated animals. Gag CM9-specific cells more closely resembled effector memory cells in expression of transcription factors than Tat SL8-specific cells, as predominantly reflected by their differential expression of $L E F 1$ and TCF7. Further, LEF1 was expressed at overall lower levels in cells from wild-type-infected animals than SIV $\Delta$ nef-vaccinated animals, mainly due to very low expression in the Gag CM9-specific cells. This difference likely reflects the much higher levels of antigen stimulation in wild-type SIV-infected animals. BATF was also expressed at lower levels in cells from wild-type-infected animals than in cells from SIV $\Delta$ nef-vaccinated animals. Since BATF has recently been shown not only to promote effector differentiation, but also to restrain the expression of the effector molecules IFN $\gamma$ and granzyme B [39], the reduced expression observed in wild-type-infected animals may reflect reduced inhibition of effector molecule expression in the presence of high viral loads. Overall, these results are consistent with previous studies suggesting virus-specific cells continue to be activated by replicating virus, and that CTL escape is associated with reduced cell activation and central memory differentiation $[3,12-14]$.

Studies in macaques using the live-attenuated SHIV89.6 vaccine suggest that protection against vaginal challenge is associated with the presence of SIV-specific $\mathrm{CD} 8^{+} \mathrm{T}$ cells in the female reproductive tract that possess both cytolytic function and some proliferative capacity $[65,66]$. Earlier studies showed that protection was associated with a higher ratio of central memory to effector memory $\mathrm{CD}^{+} \mathrm{T}$ cells in blood and lymph nodes [67]. $\mathrm{CD}^{+} \mathrm{T}$ cells from protected animals also showed higher pre-challenge measures of survival and lower apoptotic potential. In contrast to the effector memory cells found in the female reproductive tract, IL-2 secreting SIV-specific $\mathrm{CD} 8^{+} \mathrm{T}$ cells were found in lymph nodes. Overall this suggests a model whereby in protected animals, SHIV89.6 induces central memory CD8 ${ }^{+} \mathrm{T}$ cells that continually 
supply effector cells to the genital mucosa in response to persistent antigenic stimulation by replicating virus. That unprotected animals have a higher ratio of effector memory to central memory cells in blood and lymph nodes suggests that lack of protection may be associated with heightened systemic $\mathrm{T}$ cell activation and resultant apoptosis and exhaustion.

In the setting of spontaneously controlled HIV infection, overwhelming evidence suggests $\mathrm{CD}^{+} \mathrm{T}$ cell activity is critical for viral suppression. However there has been substantial heterogeneity reported in ex vivo measures of $\mathrm{CD} 8^{+} \mathrm{T}$ cell function in controllers. Studies have variously shown associations between control of viremia and $\mathrm{CD} 8^{+} \mathrm{T}$ cell polyfunctionality, HIVspecific $\mathrm{CD} 8^{+} \mathrm{T}$ cell frequency, virus suppressive capacity, or proliferative capacity [68-72]. A more recent study [73] examined individuals who control viremia to very low levels in the absence of ex vivo $\mathrm{CD}^{+} \mathrm{T}$ cell responses (weak responders), and found that these subjects maintain an HIV-specific population of central memory $\mathrm{CD}^{+} \mathrm{T}$ cells capable of suppressing HIV ex vivo. An additional study [74] showed that spontaneous protection from HIV in controllers correlates with $\mathrm{CD}^{+} \mathrm{T}$ cell memory-type responses, prolonged cytokine secretion, and cell proliferation. In the setting of elite control and very low viremia, HIV-specific $\mathrm{T}$ cells may receive less antigenic stimulation facilitating differentiation towards a more central memory phenotype.

Our data demonstrate the utility of using transcription factor expression profiling to characterize the differentiation of $\mathrm{CD}^{+} \mathrm{T}$ cells following vaccination with SIV $\Delta$ nef. Using this approach we demonstrate that SIV-specific cells isolated from vaccinated animals at time points associated with greater immune protection display a distinct pattern of expression of transcription factors that represent the presence of different proportions of $\mathrm{CD} 8^{+} \mathrm{T}$ cell memory subsets, or different levels of activation or differentiation states. The higher expression levels of a number of transcription factors in SIV-specific cells than in any purified memory subset suggests that continued activation of subsets of virus-specific cells by low-level replicating virus induces transcriptionally distinct populations of $\mathrm{CD}^{+} \mathrm{T}$ cells which may have characteristics of both central memory and effector memory cells.

\section{Materials and Methods}

\section{Ethics statement}

The 14 female Indian-derived rhesus macaque monkeys (Macaca mulatta) described in this study were housed at the New England Primate Research Center (NEPRC) in accordance with the regulations of the American Association of Accreditation of Laboratory Animal Care and the standards of the Association for Assessment and Accreditation of Laboratory Animal Care International. All protocols and procedures were approved by the relevant Institutional Animal Care and Use Committee, which was the Harvard Medical Area (HMA) Standing Committee on Animals at Harvard Medical School. All animals were housed indoors in an SOP-driven, AAALAC-accredited facility. Husbandry and care met the guidance of the Animal Welfare Regulations, OLAW reporting and the standards set forth in The Guide for the Care and Use of Laboratory Animals. All research animals were enrolled in the NEPRC behavioral management program, including an IACUC-approved plan for Environmental Enrichment for research primates. This program included regular behavioral assessments, and provision of species appropriate manipulanda, and foraging opportunities. This protocol had an IACUCapproved exemption from social housing based on scientific justification. Primary enclosures consisted of stainless steel primate caging provided by a commercial vendor. Animal body weights and cage dimensions were regularly monitored. Overall dimensions of primary enclosures (floor area and height) met the specifications of The Guide for the Care and Use of Laboratory Animals, and the Animal Welfare Regulations (AWR's). Further, all primary enclosures were sanitized every 14 days at a minimum, in compliance with AWRs. Secondary enclosures 
(room level) met specifications of The Guide with respect to temperature, humidity, lighting and noise level. The animals were provided ad lib access to municipal source water, offered commercial monkey chow twice daily, and offered fresh produce a minimum of three times weekly. Light cycle was controlled at 12/12 hours daily. The animals were subject to twice daily documented observations by trained animal care and veterinary staff, and enrolled in the facility's environmental enrichment, and preventative health care programs. Euthanasia took place at defined experimental endpoints using protocols consistent with the American Veterinary Medical Association (AVMA) guidelines. Animals were first sedated with intramuscular ketamine hydrochloride $(20 \mathrm{mg} / \mathrm{kg})$ followed by sodium pentobarbital $(\geq 100 \mathrm{mg} / \mathrm{kg})$ intravenously to achieve euthanasia.

\section{Isolation of lymphocytes}

Peripheral blood samples were collected from unvaccinated healthy rhesus macaques $(n=5)$ for purification of naïve and memory $\mathrm{CD}^{+} \mathrm{T}$ cell subsets, or Mamu- $\mathrm{A}^{*} 01^{+} \mathrm{SIV} \Delta$ nef-vaccinated animals $(\mathrm{n}=4)$ at week 5 and week 20 post-vaccination, or Mamu- $\mathrm{A}^{*} 01^{+}$wild-type SIV-infected animals $(n=5)$ at week 20 post-infection, for purification of SIV-specific cells. Blood was collected in EDTA vacutainer tubes (Becton Dickinson Vacutainer systems, Franklin Lakes, NJ), and peripheral blood mononuclear cells (PBMC) were separated by density gradient centrifugation (Lymphocyte Separation Medium; MP Biomedicals Inc., Solon, OH) at 1500 rpm for 45 minutes. PBMC from vaccinated or infected animals were cryopreserved, and subsequently thawed prior to cell sorting. PBMC from healthy uninfected animals were used immediately after separation.

\section{Plasma viral load quantification}

Total RNA copy number equivalents were determined in EDTA-treated plasma using a standardized quantitative real-time RT-PCR assay based on amplification of conserved gag sequences as described previously [75]. In wild-type SIV-infected animals, viral loads were between 22,000 and 1,900,000 copy equivalents/ml plasma at 20 weeks following infection.

\section{Cell sorting}

Naïve $\left(\mathrm{CD} 95^{-} \mathrm{CCR} 7^{+} \mathrm{CD} 28^{+}\right)$, central memory $\left(\mathrm{CD} 95^{+} \mathrm{CCR} 7^{+} \mathrm{CD} 28^{+}\right)$, transitional memory $\left(\mathrm{CD} 5^{+} \mathrm{CCR}^{-} \mathrm{CD} 28^{+}\right)$and effector memory $\left(\mathrm{CD} 5^{+} \mathrm{CCR}^{-} \mathrm{CD} 28^{-}\right) \mathrm{CD}^{+} \mathrm{T}$ cell subsets were sorted from PBMC from uninfected animals. SIV-specific $\mathrm{CD} 8^{+} \mathrm{T}$ cells were sorted from previously cryopreserved PBMC from SIVmac239 $\Delta$ nef-vaccinated or SIVmac239-infected animals. SIV-specific $\mathrm{CD} 8^{+} \mathrm{T}$ cells from Mamu- $\mathrm{A}^{*} 01^{+}$or Mamu- $\mathrm{A}^{*} 02^{+}$animals were identified using APC- or PE- conjugated Mamu-A*01 or $\mathrm{A}^{*} 02 \mathrm{MHC}$ class I tetramers or pentamers (Proimmune) complexed with the cognate CTL epitope. $\mathrm{A}^{*} 01 \mathrm{Gag}_{181-189} \mathrm{CM} 9$ [76] and $\mathrm{A}^{*} 01$ $\mathrm{Tat}_{28-35} \mathrm{SL} 8[77,78]$ tetramers were kindly provided by Nancy Wilson and David Watkins (Wisconsin National Primate Research Center, Madison, WI). To identify naïve and memory phenotypes, PBMC were stained with CD3 (SP34) FITC or Pacific Blue; CD4 (L200) PerCP-Cy5.5; CD8 (RPA-T8) Alexa 700; CD28 (28.2) ECD (Beckman Coulter), CD95 (DX2) APC, CCR7 (150503) PE (R\&D Systems). Antibodies were obtained from BD Pharmingen unless specified. PBMCs $\left(1-2 \times 10^{6}\right)$ were initially labeled with LIVE/DEAD viability stain (Life Technologies) and washed; incubated with CCR7 antibody for $15 \mathrm{~min}$ at 37C; incubated with tetramers or pentamers for $10 \mathrm{~min}$ at RT and washed; then incubated with all other antibodies for 20 min at RT and washed prior to sorting. Cell sorting was performed on a FACS Aria II cell sorter (BD Biosciences). Sorts were $>99 \%$ pure for all populations, and cell yields generally ranged between $10^{3}$ and $10^{5}$ cells. 


\section{RNA extraction, cDNA synthesis and real time PCR}

Total RNA was isolated using RNeasy Plus Micro Kit (74034, Qiagen) and quantified from $\mathrm{CD}^{+} \mathrm{T}$ cells that were FACS purified from PBMC. cDNA was synthesized using the HighCapacity Reverse Transcription Kit with RNase Inhibitor (4374966, Life Technologies). The resulting cDNA (1ng equivalent input) per reaction was subjected to 18 cycles of preamplification using the ABI Preamp Master Mix kit and pooled TaqMan assays (S1 Table) (Applied Biosystems, Life Technologies). Preamplified cDNAs were diluted 5-fold with $1 \times$ TE and loaded on 96x96 Fluidigm BioMark dynamic arrays (Fluidigm) along with the selected real-time PCR assays. All possible combinations of samples and assays on the BioMark dynamic array chip were mixed using the Fluidigm (IFC) integrated fluidic circuit controller. The Fluidigm Biomark System was used for real time PCR amplification and data collection, using 40 cycles of amplification with real-time monitoring of FAM fluorescence in each well. Initial calculations of cycle thresholds $(\mathrm{Ct})$ were performed using the Fluidigm BioMark software and further analysis was carried out using GenEx software (MultiD Analyses, URL: http://www.multid.se). Offscale-low expression values were set to maximum onscale $\mathrm{Ct}+1$ for each target transcript. Five endogenous control genes were included in each Fluidigm run and the stability of endogenous control genes across all experimental samples was analyzed using the NormFinder algorithm in GenEx. The mean expression of the two most stable endogenous control genes ( $P G K 1$ and $T B P)$ was used for normalization. Relative expression $\left(2^{-\Delta c t}\right)$ values were $\log _{2}$ transformed for subsequent analyses (S1 Dataset).

\section{Cluster analyses}

Unsupervised agglomerative hierarchical clustering was performed on transcript meancentered expression values using the Euclidean distance metric and complete linkage clustering method. Principal component analysis was performed using un-scaled expression values. PCA heatmap expression values were normalized by scaling expression values to the range of each transcript. RORC was excluded from PCA analyses because RORC was expressed at or below the limit of detection in the majority of SIV-specific cells, and chip-to-chip differences in the values assigned to offscale-low reactions introduced artifacts of apparent differential expression that confounded PCA plot structure. Clustering analyses were performed using R [79], and the functions prcomp \{stats\}, and hclust \{stats\}. In addition to base $\mathrm{R}$ the following $\mathrm{R}$ packages were used: RColorBrewer [80], Plotrix [81], gplots [82], lme4 [83].

\section{Statistical analyses}

Statistical analyses were performed using both Stata software (StataCorp. 2013. Stata Statistical Software: Release 13. College Station, TX: StataCorp LP) and R [79]. Differences in transcription factor expression between sorted naïve and memory subsets, and differences between sorted subsets and SIV-specific cells were assessed by one-way ANOVA. Differences in principal component plot positions of SIV-specific cells and sorted naïve and memory cell subsets were assessed by unpaired Student's $t$-test of PC3 values. Differences in principal component plot positions of week 5 and week 20 post-vaccination samples and of Gag CM9- and Tat SL8-specific samples were assessed by mixed effects linear regression modeling of PC1 values of a principal component analysis of SIV-specific cells. Differences between individual transcription factor expression values at week 5 and week 20 post-vaccination or infection, or between Gag CM9- and Tat SL8-specific cells, were assessed using mixed effects linear regression models. Differences between individual transcription factor expression values in cells isolated at 20 weeks post SIV $\Delta$ nef vaccination and wild-type SIV infection were assessed by unpaired Student's $t$-test. Differences in frequencies of $\mathrm{CD}^{+} \mathrm{T}$ cell memory subsets in Gag CM9-and 
Tat SL8-specific cells were assessed by unpaired Student's $t$-test (week 5 vs. week 20) or paired Student's $t$-test (Gag vs. Tat.)

\title{
Target transcript and Entrez Gene ID
}

\author{
AHR 714254 \\ BATF 702646 \\ BCL6 708736 \\ BCL11B 705238 \\ BCOR 698644 \\ PRDM1 696757 \\ EOMES 704711 \\ ID2 693394 \\ RORC 717052 \\ RORA 704014 \\ PBX3 711691 \\ NFIL3 704757 \\ IRF4 722883 \\ RUNX3 719447 \\ TBX21 694044 \\ TCF7 710234 \\ LEF1 695776 \\ GATA3 713840
}

\section{Supporting Information}

S1 Table. TaqMan assays. The qPCR primer/probe sets (TaqMan assays) used to quantify mRNA levels of the indicated target transcripts. (PDF)

S1 Dataset. Expression data. qPCR expression data $\left(\log _{2} 2^{-\Delta c t}\right)$. (XLSX)

S1 Fig. Representative FACS gating. $\mathrm{CD}^{+}$naïve and memory T cell subsets (A) and Gag CM9 and Tat SL8 tetramer/pentamer-sorted CD8 ${ }^{+}$T cells (B). (EPS)

S2 Fig. Memory phenotype of SIV-specific $\mathrm{CD8}^{+} \mathrm{T}$ cells and correlation of phenotype with transcription factor expression profile. (A) Frequencies of $\mathrm{CM}\left(\mathrm{CCR} 7^{+} \mathrm{CD} 28^{+}\right)$, TM (CCR7 $\mathrm{CD} 28^{+}$), and EM (CCR7 ${ }^{-} \mathrm{CD}^{-} 8^{-}$) populations present in Gag CM9- and Tat SL8-specific CD8 ${ }^{+}$ $\mathrm{T}$ cells were analyzed by flow cytometry. Statistically significant $(\mathrm{p} \leq 0.05)$ differences in frequencies are indicated by bars with asterisks. (B) Pearson's correlation between the ratio of \% EM to \%CM cells and the transcription factor expression profile PCA PC2 value for each sample of Gag CM9- and Tat SL8-specific CD8 ${ }^{+}$T cells. (EPS)

S1 Video. Principal Component Analysis of PC1, PC2 and PC3. Naïve (dark blue), EM (red), TM (orange), CM (green), week 5 p.v. (pink) and week 20 p.v. (light blue) SIV-specific cell samples are presented.

(MP4) 


\section{Acknowledgments}

We thank David Evans for providing samples of blood from SIV-infected animals, Angela Carville and members of the NEPRC Primate Medicine staff for expert animal care, and Carolyn O'Toole and Noel Bane for expert editorial assistance.

\section{Author Contributions}

Conceived and designed the experiments: RPJ JMB PAR NCS YVK HSH. Performed the experiments: JMB PAR MAC. Analyzed the data: RPJ JMB PAR MAC HjK WL SA. Contributed reagents/materials/analysis tools: RKR QL ATH. Wrote the paper: RPJ JMB PAR MAC.

\section{References}

1. Daniel MD, Kirchhoff F, Czajak SC, Sehgal PK, Desrosiers RC (1992) Protective effects of a live attenuated SIV vaccine with a deletion in the nef gene. Science 258: 1938-1941. PMID: 1470917

2. Almond N, Kent K, Cranage M, Rud E, Clarke B, et al. (1995) Protection by attenuated simian immunodeficiency virus in macaques against challenge with virus-infected cells. Lancet 345: 1342-1344. PMID: 7752758

3. Johnson RP, Lifson JD, Czajak SC, Cole KS, Manson KH, et al. (1999) Highly attenuated vaccine strains of simian immunodeficiency virus protect against vaginal challenge: inverse relationship of degree of protection with level of attenuation. J Virol 73: 4952-4961. PMID: 10233957

4. Baba TW, Liska V, Khimani AH, Ray NB, Dailey PJ, et al. (1999) Live attenuated, multiply deleted simian immunodeficiency virus causes AIDS in infant and adult macaques. Nat Med 5: 194-203. PMID: 9930868

5. Baba TW, Jeong YS, Pennick D, Bronson R, Greene MF, et al. (1995) Pathogenicity of live, attenuated SIV after mucosal infection of neonatal macaques. Science 267: 1820-1825. PMID: 7892606

6. Schmitz JE, Johnson RP, McClure HM, Manson KH, Wyand MS, et al. (2005) Effect of CD8+ lymphocyte depletion on virus containment after simian immunodeficiency virus SIVmac251 challenge of live attenuated SIVmac239delta3-vaccinated rhesus macaques. J Virol 79: 8131-8141. PMID: 15956558

7. Johnson RP, Glickman RL, Yang JQ, Kaur A, Dion JT, et al. (1997) Induction of vigorous cytotoxic Tlymphocyte responses by live attenuated simian immunodeficiency virus. J Virol 71: 7711-7718. PMID: 9311855

8. Gauduin MC, Glickman RL, Ahmad S, Yilma T, Johnson RP (1999) Immunization with live attenuated simian immunodeficiency virus induces strong type $1 \mathrm{~T}$ helper responses and beta-chemokine production. Proc Natl Acad Sci USA 96: 14031-14036. PMID: 10570193

9. Cole KS, Rowles JL, Jagerski BA, Murphey-Corb M, Unangst T, et al. (1997) Evolution of envelopespecific antibody responses in monkeys experimentally infected or immunized with simian immunodeficiency virus and its association with the development of protective immunity. J Virol 71: 5069-5079. PMID: 9188572

10. Li Q, Zeng M, Duan L, Voss JE, Smith AJ, et al. (2014) Live simian immunodeficiency virus vaccine correlate of protection: local antibody production and concentration on the path of virus entry. J Immunol 193: 3113-3125. doi: 10.4049/jimmunol.1400820 PMID: 25135832

11. Metzner KJ, Jin X, Lee FV, Gettie A, Bauer DE, et al. (2000) Effects of in vivo CD8(+) T cell depletion on virus replication in rhesus macaques immunized with a live, attenuated simian immunodeficiency virus vaccine. J Exp Med 191: 1921-1931. PMID: 10839807

12. Sasikala-Appukuttan AK, Kim HO, Kinzel NJ, Hong JJ, Smith AJ, et al. (2013) Location and Dynamics of the Immunodominant CD8 T Cell Response to SIVDeltanef Immunization and SIVmac251 Vaginal Challenge. PLoS One 8: e81623. doi: 10.1371/journal.pone.0081623 PMID: 24349100

13. Fukazawa Y, Park H, Cameron MJ, Lefebvre F, Lum R, et al. (2012) Lymph node T cell responses predict the efficacy of live attenuated SIV vaccines. Nat Med 18: 1673-1681. doi: 10.1038/nm.2934 PMID: 22961108

14. Salisch NC, Kaufmann DE, Awad AS, Reeves RK, Tighe DP, et al. (2010) Inhibitory TCR coreceptor PD-1 is a sensitive indicator of low-level replication of SIV and HIV-1. J Immunol 184: 476-487. doi: 10 4049/jimmunol.0902781 PMID: 19949078

15. Cromwell MA, Veazey RS, Altman JD, Mansfield KG, Glickman R, et al. (2000) Induction of mucosal homing virus-specific CD8(+) T lymphocytes by attenuated simian immunodeficiency virus. J Virol 74: 8762-8766. PMID: 10954580 
16. Horton H, Vogel TU, Carter DK, Vielhuber K, Fuller DH, et al. (2002) Immunization of rhesus macaques with a DNA prime/modified vaccinia virus Ankara boost regimen induces broad simian immunodeficiency virus (SIV)-specific T-cell responses and reduces initial viral replication but does not prevent disease progression following challenge with pathogenic SIVmac239. J Virol 76: 7187-7202. PMID: 12072518

17. Hanke T, Samuel RV, Blanchard TJ, Neumann VC, Allen TM, et al. (1999) Effective induction of simian immunodeficiency virus-specific cytotoxic T lymphocytes in macaques by using a multiepitope gene and DNA prime-modified vaccinia virus Ankara boost vaccination regimen. J Virol 73: 7524-7532. PMID: 10438842

18. Connor RI, Montefiori DC, Binley JM, Moore JP, Bonhoeffer S, et al. (1998) Temporal analyses of virus replication, immune responses, and efficacy in rhesus macaques immunized with a live, attenuated simian immunodeficiency virus vaccine. J Virol 72: 7501-7509. PMID: 9696847

19. Kirchhoff F, Kestler HWI, Desrosiers RC (1994) Upstream U3 sequences in simian immunodeficiency virus are selectively deleted in vivo in the absence of an intact nef gene. J Virol 68: 2031-2037. PMID: 8107267

20. Kestler HW III, Ringler DJ, Mori K, Panicali DL, Sehgal PK, et al. (1991) Importance of the nef gene for maintenance of high virus loads and for development of AIDS. Cell 65: 651-662. PMID: 2032289

21. Burwitz BJ, Ende Z, Sudolcan B, Reynolds MR, Greene JM, et al. (2011) Simian Immunodeficiency Virus SIVmac239\{Delta\}nef Vaccination Elicits Different Tat28-35SL8-Specific CD8+ T-Cell Clonotypes Compared to a DNA Prime/Adenovirus Type 5 Boost Regimen in Rhesus Macaques. J Virol 85: 3683-3689. doi: 10.1128/JVI.02112-10 PMID: 21270159

22. Kaech SM, Cui W (2012) Transcriptional control of effector and memory CD8+ T cell differentiation. Nat Rev Immunol 12: 749-761. doi: 10.1038/nri3307 PMID: 23080391

23. Vaquerizas JM, Kummerfeld SK, Teichmann SA, Luscombe NM (2009) A census of human transcription factors: function, expression and evolution. Nat Rev Genet 10: 252-263. doi: 10.1038/nrg2538 PMID: 19274049

24. Novershtern N, Subramanian A, Lawton LN, Mak RH, Haining WN, et al. (2011) Densely interconnected transcriptional circuits control cell states in human hematopoiesis. Cell 144:296-309. doi: 10.1016/ j.cell.2011.01.004 PMID: 21241896

25. Levine M, Tjian R (2003) Transcription regulation and animal diversity. Nature 424: 147-151. PMID: 12853946

26. Doering TA, Crawford A, Angelosanto JM, Paley MA, Ziegler CG, et al. (2012) Network analysis reveals centrally connected genes and pathways involved in CD8+ T cell exhaustion versus memory. Immunity 37: 1130-1144. doi: 10.1016/j.immuni.2012.08.021 PMID: 23159438

27. Ravasi T, Suzuki H, Cannistraci CV, Katayama S, Bajic VB, et al. (2010) An atlas of combinatorial transcriptional regulation in mouse and man. Cell 140: 744-752. doi: 10.1016/j.cell.2010.01.044 PMID: 20211142

28. Intlekofer AM, Takemoto N, Wherry EJ, Longworth SA, Northrup JT, et al. (2005) Effector and memory CD8+ T cell fate coupled by T-bet and eomesodermin. Nat Immunol 6: 1236-1244. PMID: 16273099

29. Joshi NS, Cui W, Chandele A, Lee HK, Urso DR, et al. (2007) Inflammation directs memory precursor and short-lived effector CD8(+) T cell fates via the graded expression of T-bet transcription factor. Immunity 27: 281-295. PMID: 17723218

30. Pearce EL, Mullen AC, Martins GA, Krawczyk CM, Hutchins AS, et al. (2003) Control of effector CD8+ T cell function by the transcription factor Eomesodermin. Science 302: 1041-1043. PMID: 14605368

31. Takemoto N, Intlekofer AM, Northrup JT, Wherry EJ, Reiner SL (2006) Cutting Edge: IL-12 inversely regulates T-bet and eomesodermin expression during pathogen-induced CD8+ T cell differentiation. $J$ Immunol 177: 7515-7519. PMID: 17114419

32. Kallies A, Xin A, Belz GT, Nutt SL (2009) Blimp-1 transcription factor is required for the differentiation of effector CD8(+) T cells and memory responses. Immunity 31: 283-295. doi: 10.1016/j.immuni.2009. 06.021 PMID: 19664942

33. Rutishauser RL, Martins GA, Kalachikov S, Chandele A, Parish IA, et al. (2009) Transcriptional repressor Blimp-1 promotes CD8(+) T cell terminal differentiation and represses the acquisition of central memory T cell properties. Immunity 31: 296-308. doi: 10.1016/j.immuni.2009.05.014 PMID: 19664941

34. Yang CY, Best JA, Knell J, Yang E, Sheridan AD, et al. (2011) The transcriptional regulators Id2 and Id3 control the formation of distinct memory CD8+ T cell subsets. Nat Immunol 12: 1221-1229. doi: 10. 1038/ni.2158 PMID: 22057289

35. Cannarile MA, Lind NA, Rivera R, Sheridan AD, Camfield KA, et al. (2006) Transcriptional regulator Id2 mediates CD8+ T cell immunity. Nat Immunol 7: 1317-1325. PMID: 17086188 
36. Masson F, Minnich M, Olshansky M, Bilic I, Mount AM, et al. (2013) Id2-mediated inhibition of E2A represses memory CD8+ T cell differentiation. J Immunol 190: 4585-4594. doi: 10.4049/jimmunol. 1300099 PMID: 23536629

37. Kuroda S, Yamazaki M, Abe M, Sakimura K, Takayanagi H, et al. (2011) Basic leucine zipper transcription factor, ATF-like (BATF) regulates epigenetically and energetically effector CD8 T-cell differentiation via Sirt1 expression. Proc Natl Acad Sci U S A 108: 14885-14889. doi: 10.1073/pnas.1105133108 PMID: 21873234

38. Quigley M, Pereyra F, Nilsson B, Porichis F, Fonseca C, et al. (2010) Transcriptional analysis of HIVspecific CD8+ T cells shows that PD- 1 inhibits T cell function by upregulating BATF. Nat Med 16: 1147-1151. doi: 10.1038/nm.2232 PMID: 20890291

39. Kurachi M, Barnitz RA, Yosef N, Odorizzi PM, Dilorio MA, et al. (2014) The transcription factor BATF operates as an essential differentiation checkpoint in early effector CD8+ T cells. Nat Immunol 15: 373-383. doi: 10.1038/ni.2834 PMID: 24584090

40. Cruz-Guilloty F, Pipkin ME, Djuretic IM, Levanon D, Lotem J, et al. (2009) Runx3 and T-box proteins cooperate to establish the transcriptional program of effector CTLs. J Exp Med 206: 51-59. doi: 10.1084/ jem.20081242 PMID: 19139168

41. Zhang S, Rozell M, Verma RK, Albu DI, Califano D, et al. (2010) Antigen-specific clonal expansion and cytolytic effector function of CD8+ T lymphocytes depend on the transcription factor Bcl11b. J Exp Med 207: 1687-1699. doi: 10.1084/jem.20092136 PMID: 20660613

42. Vanvalkenburgh J, Albu DI, Bapanpally C, Casanova S, Califano D, et al. (2011) Critical role of Bcl11b in suppressor function of $\mathrm{T}$ regulatory cells and prevention of inflammatory bowel disease. J Exp Med 208: 2069-2081. doi: 10.1084/jem.20102683 PMID: 21875956

43. Kastner P, Chan S, Vogel WK, Zhang LJ, Topark-Ngarm A, et al. (2010) Bcl11b represses a mature Tcell gene expression program in immature CD4(+)CD8(+) thymocytes. Eur J Immunol 40: 2143-2154. doi: 10.1002/eji.200940258 PMID: 20544728

44. Willinger $\mathrm{T}$, Freeman $\mathrm{T}$, Herbert $\mathrm{M}$, Hasegawa $\mathrm{H}$, McMichael AJ, et al. (2006) Human naive CD8 T cells down-regulate expression of the WNT pathway transcription factors lymphoid enhancer binding factor 1 and transcription factor 7 (T cell factor-1) following antigen encounter in vitro and in vivo. J Immunol 176: 1439-1446. PMID: 16424171

45. Zhou X, Yu S, Zhao DM, Harty JT, Badovinac VP, et al. (2010) Differentiation and persistence of memory CD8(+) T cells depend on T cell factor 1. Immunity 33: 229-240. doi: 10.1016/j.immuni.2010.08.002 PMID: 20727791

46. Best JA, Blair DA, Knell J, Yang E, Mayya V, et al. (2013) Transcriptional insights into the CD8(+) T cell response to infection and memory T cell formation. Nat Immunol 14: 404-412. doi: 10.1038/ni.2536 PMID: 23396170

47. Billerbeck E, Kang YH, Walker L, Lockstone H, Grafmueller S, et al. (2010) Analysis of CD161 expression on human CD8+ T cells defines a distinct functional subset with tissue-homing properties. Proc Natl Acad Sci U S A 107: 3006-3011. doi: 10.1073/pnas.0914839107 PMID: 20133607

48. Tai TS, Pai SY, Ho IC (2013) GATA-3 regulates the homeostasis and activation of CD8+ T cells. J Immunol 190: 428-437. doi: 10.4049/jimmunol.1201361 PMID: 23225883

49. Curtis MM, Way SS, Wilson CB (2009) IL-23 promotes the production of IL-17 by antigen-specific CD8 T cells in the absence of IL-12 and type-I interferons. J Immunol 183: 381-387. doi: 10.4049/jimmunol. 0900939 PMID: 19542449

50. Johnson RP, Desrosiers RC (1998) Protective immunity induced by live attenuated SIV. Curr Opp Immunol 10: 436-443. PMID: 9722920

51. Barouch DH, Kunstman J, Kuroda MJ, Schmitz JE, Santra S, et al. (2002) Eventual AIDS vaccine failure in a rhesus monkey by viral escape from cytotoxic T lymphocytes. Nature 415: 335-339. PMID: 11797012

52. Allen TM, O'Connor DH, Jing P, Dzuris JL, Mothe BR, et al. (2000) Tat-specific cytotoxic T lymphocytes select for SIV escape variants during resolution of primary viraemia. Nature 407: 386-390. PMID: 11014195

53. Bimber BN, Burwitz BJ, O'Connor S, Detmer A, Gostick E, et al. (2009) Ultradeep pyrosequencing detects complex patterns of CD8+ T-lymphocyte escape in simian immunodeficiency virus-infected macaques. J Virol 83: 8247-8253. doi: 10.1128/JVI.00897-09 PMID: 19515775

54. Huynh KD, Fischle W, Verdin E, Bardwell VJ (2000) BCoR, a novel corepressor involved in BCL-6 repression. Genes Dev 14: 1810-1823. PMID: 10898795

55. Ichii H, Sakamoto A, Hatano M, Okada S, Toyama H, et al. (2002) Role for Bcl-6 in the generation and maintenance of memory CD8+ T cells. Nat Immunol 3: 558-563. PMID: 12021781 
56. Nayar R, Enos M, Prince A, Shin H, Hemmers S, et al. (2012) TCR signaling via Tec kinase ITK and interferon regulatory factor 4 (IRF4) regulates CD8+ T-cell differentiation. Proc Natl Acad Sci U S A 109: E2794-2802. doi: 10.1073/pnas.1205742109 PMID: 23011795

57. Jameson SC, Masopust D (2009) Diversity in T cell memory: an embarrassment of riches. Immunity 31: 859-871. doi: 10.1016/j.immuni.2009.11.007 PMID: 20064446

58. Sallusto F, Lenig D, Forster R, Lipp M, Lanzavecchia A (1999) Two subsets of memory T lymphocytes with distinct homing potentials and effector functions. Nature 401: 708-712. PMID: 10537110

59. Sallusto F, Geginat J, Lanzavecchia A (2004) Central memory and effector memory T cell subsets: function, generation, and maintenance. Annu Rev Immunol 22: 745-763. PMID: 15032595

60. Pitcher CJ, Hagen SI, Walker JM, Lum R, Mitchell BL, et al. (2002) Development and homeostasis of T cell memory in rhesus macaque. J Immunol 168: 29-43. PMID: 11751943

61. Crotty S, Johnston RJ, Schoenberger SP (2010) Effectors and memories: Bcl-6 and Blimp-1 in T and B lymphocyte differentiation. Nat Immunol 11: 114-120. doi: 10.1038/ni.1837 PMID: 20084069

62. Wherry EJ (2011) T cell exhaustion. Nat Immunol 12: 492-499. PMID: 21739672

63. Youngblood B, Wherry EJ, Ahmed R (2012) Acquired transcriptional programming in functional and exhausted virus-specific CD8 T cells. Curr Opin HIV AIDS 7: 50-57. doi: 10.1097/COH. Ob013e32834ddcf2 PMID: 22134341

64. Hong JJ, Amancha PK, Rogers K, Ansari AA, Villinger F (2013) Re-evaluation of PD-1 expression by T cells as a marker for immune exhaustion during SIV infection. PLoS One 8: e60186. doi: 10.1371/ journal.pone.0060186 PMID: 23555918

65. Genesca M, Skinner PJ, Hong JJ, Li J, Lu D, et al. (2008) With minimal systemic T-cell expansion, CD8 $+T$ Cells mediate protection of rhesus macaques immunized with attenuated simian-human immunodeficiency virus SHIV89.6 from vaginal challenge with simian immunodeficiency virus. J Virol 82: 11181-11196. doi: 10.1128/JVI.01433-08 PMID: 18787003

66. Genesca M, Skinner PJ, Bost KM, Lu D, Wang Y, et al. (2008) Protective attenuated lentivirus immunization induces SIV-specific T cells in the genital tract of rhesus monkeys. Mucosal Immunol 1:219-228. doi: 10.1038/mi.2008.6 PMID: 19079181

67. Genesca M, Rourke T, Li J, Bost K, Chohan B, et al. (2007) Live attenuated lentivirus infection elicits polyfunctional simian immunodeficiency virus Gag-specific CD8+ T cells with reduced apoptotic susceptibility in rhesus macaques that control virus replication after challenge with pathogenic SIVmac239. Journal of Immunology 179: 4732-4740. PMID: 17878372

68. Betts MR, Nason MC, West SM, De Rosa SC, Migueles SA, et al. (2006) HIV nonprogressors preferentially maintain highly functional HIV-specific CD8+ T cells. Blood 107: 4781-4789. PMID: 16467198

69. Chen H, Piechocka-Trocha A, Miura T, Brockman MA, Julg BD, et al. (2009) Differential neutralization of human immunodeficiency virus (HIV) replication in autologous CD4 T cells by HIV-specific cytotoxic T lymphocytes. J Virol 83: 3138-3149. doi: 10.1128/JVI.02073-08 PMID: 19158248

70. Julg B, Williams KL, Reddy S, Bishop K, Qi Y, et al. (2010) Enhanced anti-HIV functional activity associated with Gag-specific CD8 T-cell responses. J Virol 84: 5540-5549. doi: 10.1128/JVI.02031-09 PMID: 20335261

71. Saez-Cirion A, Lacabaratz C, Lambotte O, Versmisse P, Urrutia A, et al. (2007) HIV controllers exhibit potent CD8 T cell capacity to suppress HIV infection ex vivo and peculiar cytotoxic T lymphocyte activation phenotype. Proc Natl Acad Sci U S A 104: 6776-6781. PMID: 17428922

72. Migueles SA, Laborico AC, Shupert WL, Sabbaghian MS, Rabin R, et al. (2002) HIV-specific CD8+ T cell proliferation is coupled to perforin expression and is maintained in nonprogressors. Nature Immunology 3: 1061-1068. PMID: 12368910

73. Ndhlovu ZM, Proudfoot J, Cesa K, Alvino DM, McMullen A, et al. (2012) Elite controllers with low to absent effector CD8+ T cell responses maintain highly functional, broadly directed central memory responses. J Virol 86: 6959-6969. doi: 10.1128/JVI.00531-12 PMID: 22514340

74. Ndhlovu ZM, Chibnik LB, Proudfoot J, Vine S, McMullen A, et al. (2013) High-dimensional immunomonitoring models of HIV-1-specific CD8 T-cell responses accurately identify subjects achieving spontaneous viral control. Blood 121: 801-811. doi: 10.1182/blood-2012-06-436295 PMID: 23233659

75. Cline AN, Bess JW, Piatak M Jr., Lifson JD (2005) Highly sensitive SIV plasma viral load assay: practical considerations, realistic performance expectations, and application to reverse engineering of vaccines for AIDS. J Med Primatol 34: 303-312. PMID: 16128925

76. Allen TM, Sidney J, delGuercio M-F, Glickman RL, Lensmeyer GL, et al. (1998) Characterization of the peptide binding motif of a rhesus MHC class I molecule (Mamu-A*01) that binds an immunodominant CTL epitope from SIV. J Immunol 160: 6062-6071. PMID: 9637523

77. Allen TM, Mothe BR, Sidney J, Jing P, Dzuris JL, et al. (2001) CD8(+) lymphocytes from simian immunodeficiency virus-infected rhesus macaques recognize 14 different epitopes bound by the major 
histocompatibility complex class I molecule mamu-A*01: implications for vaccine design and testing. $\mathrm{J}$ Virol 75: 738-749. PMID: 11134287

78. Kuroda M, Schmitz JE, Barouch DH, Craiu A, Allen TM, et al. (1998) Analysis of gag-specific cytotoxic T lymphocytes in simian immunodeficiency virus-infected rhesus monkeys by cell staining with a tetrameric major histocompatibility complex class I-peptide complex. J Exp Med 187: 1373-1381. PMID: 9565630

79. R Core Team (2014) R: A language and environment for statistical computing. R Foundation for Statistical Computing, Vienna, Austria. ISBN 3-900051-07-0, URL http://www.R-project.org/.

80. Neuwirth E (2011) RColorBrewer: ColorBrewer palettes. R package version 1.0-5. http://CRAN.Rproject.org/package=RColorBrewer.

81. Lemon J (2006) Plotrix: a package in the red light district of R. R-News, 6(4): 8-12.

82. Warnes GR, Bolker B, Bonebakker L, Gentleman R, Huber W, et al. (2014) gplots: Various R programming tools for plotting data. $R$ package version 2.13.0. http://CRAN.R-project.org/package = gplots.

83. Bates D, Maechler M, Bolker B, Walker S (2014) Ime4: Linear mixed-effects models using Eigen and S4. $\mathrm{R}$ package version 1.1-6. http://CRAN.R-project.org/package = Ime4.

84. Kiss EA, Vonarbourg C, Kopfmann S, Hobeika E, Finke D, et al. (2011) Natural aryl hydrocarbon receptor ligands control organogenesis of intestinal lymphoid follicles. Science 334: 1561-1565. doi: 10. 1126/science.1214914 PMID: 22033518

85. Li Y, Innocentin S, Withers DR, Roberts NA, Gallagher AR, et al. (2011) Exogenous stimuli maintain intraepithelial lymphocytes via aryl hydrocarbon receptor activation. Cell 147:629-640. doi: 10.1016/j. cell.2011.09.025 PMID: 21999944

86. Wherry EJ, Ha SJ, Kaech SM, Haining WN, Sarkar S, et al. (2007) Molecular signature of CD8+ T cell exhaustion during chronic viral infection. Immunity 27: 670-684. PMID: 17950003

87. Berkes CA, Bergstrom DA, Penn BH, Seaver KJ, Knoepfler PS, et al. (2004) Pbx marks genes for activation by $\mathrm{MyOD}$ indicating a role for a homeodomain protein in establishing myogenic potential. Mol Cell 14: 465-477. PMID: 15149596

88. Cretney E, Xin A, Shi W, Minnich M, Masson F, et al. (2011) The transcription factors Blimp-1 and IRF4 jointly control the differentiation and function of effector regulatory T cells. Nat Immunol 12: 304-311. doi: 10.1038/ni.2006 PMID: 21378976

89. Mittrucker HW, Matsuyama T, Grossman A, Kundig TM, Potter J, et al. (1997) Requirement for the transcription factor LSIRF/IRF4 for mature B and T lymphocyte function. Science 275: 540-543. PMID: 8999800

90. Zhang W, Zhang J, Kornuc M, Kwan K, Frank R, et al. (1995) Molecular cloning and characterization of NF-IL3A, a transcriptional activator of the human interleukin-3 promoter. Mol Cell Biol 15: 6055-6063. PMID: 7565758

91. Fuchs A, Vermi W, Lee JS, Lonardi S, Gilfillan S, et al. (2013) Intraepithelial type 1 innate lymphoid cells are a unique subset of IL-12- and IL-15-responsive IFN-gamma-producing cells. Immunity 38 : 769-781. doi: 10.1016/j.immuni.2013.02.010 PMID: 23453631 